\title{
Matrix Metalloproteinase-9 and Cell Division in Neuroblastoma Cells and Bone Marrow Macrophages
}

\author{
M. Gloria Sans-Fons, Sonia Sole, Coral Sanfeliu, \\ and Anna M. Planas

\begin{abstract}
From the Department of Brain Ischemia and Neurodegeneration, Institut d'Investigacions Biomèdiques de Barcelona-Consejo Superior de Investigaciones Científicas, Institut d'Investigacions Biomèdiques August Pi i Sunyer, Barcelona, Spain
\end{abstract}

Matrix metalloproteinases (MMPs) degrade the extracellular matrix and carry out key functions in cell development, cancer, injury, and regeneration. In addition to its well recognized extracellular action, functional intracellular MMP activity under certain conditions is supported by increasing evidence. In this study, we observed higher gelatinase activity by in situ zymography and increased MMP-9 immunoreactivity in human neuroblastoma cells and in bone marrow macrophages undergoing mitosis compared with resting cells. We studied the pattern of immunoreactivity at the different stages of cell division by confocal microscopy. Immunostaining with different monoclonal antibodies against MMP-9 revealed a precise, dynamic, and well orchestrated localization of MMP-9 at the different stages of cell division. The cellular distribution of MMP-9 staining was studied in relation to that of microtubules. The spatial pattern of MMP-9 immunoreactivity suggested some participation in both the reorganization of the nuclear content and the process of chromatid segmentation. We then used several MMP-9 inhibitors to find out whether MMP-9 might be involved in the cell cycle. These drugs impaired the entry of cells into mitosis, as revealed by flow cytometry, and reduced cell culture growth. In addition, the silencing of MMP-9 expression with small interfering RNA also reduced cell growth. Taken together, these results suggest that intracellular MMP-9 is involved in the process of cell division in neuroblastoma cells and in primary cultures of macrophages. (Am J Pathol 2010, 177:2870-2885; DOI: 10.2353/ajpath.2010.090050)

Matrix metalloproteinases (MMPs) are zinc-dependent endopeptidases that degrade several components of the extracellular matrix. MMPs are normally found as latent zymogens that become active through proteolytic cleavage $^{1}$ by mechanisms ensuring sensitive and complex regulation of MMP activity in vivo. ${ }^{2}$ The matrix undergoes intense remodeling during development, neoplasia, inflammation, and tissue injury and recovery, which often involves enhanced release of certain proteases. MMPs are thought to have key functions in various pathological conditions, such as diseases of the central nervous system $^{3}$ and cancer. ${ }^{4}$ Indeed, invasiveness requires that tumoral cells degrade the basement membrane, and this is associated with release of MMPs. ${ }^{4}$ In accordance, MMP inhibitors attenuate tumor cell growth and/or invasive capacity. ${ }^{5,6}$ For instance, MMP inhibitors with a broad inhibitory spectrum suppress cervical lymph node metastasis. $^{7}$ Furthermore, increased MMP-9 expression is associated with enhanced proliferative capacity in mouse aortic smooth muscle cells, ${ }^{8}$ and mice injected with lymphoma cells constitutively expressing MMP-9 develop thymic lymphoma more rapidly than mice injected with control lymphoma cells. ${ }^{9}$

Growth factors up-regulate certain MMPs, such as gelatinases MMP-2 and MMP-9, in gliomas. ${ }^{10}$ MMPs are downstream targets of the epidermal growth factor receptor (EGFR) signaling pathway. ${ }^{11}$ Indeed, exposure of breast or carcinoma cells to EGFR ligands increases cell proliferation and induction of MMP- $9,{ }^{12-14}$ which is mediated by mitogen-activated protein kinases. ${ }^{15}$ In addition, the EGFR signaling pathway is associated with the proteolytic and invasive phenotype in head and neck squamous cell carcinomas. ${ }^{16}$ Transforming growth factor- $\alpha$ (TGF- $\alpha$ ) is a ligand for EGFR with mitogenic activity for epithelial and mesenchymal cells. ${ }^{17,18}$ TGF- $\alpha$ enhances MMP-9 in cervical-carcinoma SKG-IIlb cells. ${ }^{19}$

Supported by a grant from the Spanish Ministry of Education and Science (Comisión Interministerial de Ciencia y Tecnologica, SAF2005-05793 and SAF2008-04515-C02-01).

Accepted for publication August 19, 2010.

Supplemental material for this article can be found on http://ajp. amjpathol.org

Address reprint requests to Anna M. Planas, Ph.D., Department of Brain Ischemia and Neurodegeneration, IIBB-CSIC, IDIBAPS, Rossello, 161, Planta 6, E-08036, Barcelona, Spain. E-mail: anna.planas@iibb.csic.es. 
Although MMPs exert multiple functions in the extracellular space, several lines of evidence support the possibility that MMPs could also play roles in functions inside the cells. ${ }^{20,21}$ In this study we examined the intracellular expression and activation of MMP-9 in neuroblastoma cells and in primary cultures of rat macrophages, the effects of MMP-9 inhibitors or of silencing MMP-9 expression in cell cycle and/or cell growth, and the response to growth stimulation with TGF- $\alpha$. The results suggest that MMP-9 is involved in certain steps of cell division in neuroblastoma cells and in macrophages.

\section{Materials and Methods}

\section{Neuroblastoma Cell Cultures and Drug Treatments}

Human neuroblastoma SH-SY5Y cells (European Collection of Cell Cultures, Salisbury, Wiltshire, UK) were grown in Ham's F12 and Eagle's minimal essential medium (1:1) containing $15 \%$ fetal calf serum, $1 \%$ nonessential amino acids, $2 \mathrm{mmol} / \mathrm{L}$ glutamine, and $20 \mu \mathrm{g} / \mathrm{ml}$ gentamicin at $37^{\circ} \mathrm{C}$ and $5 \% \mathrm{CO}_{2}$ in a humidified atmosphere. N-Myc amplified human neuroblastoma SK-N-BE-2C cells were kindly provided by Dr. Jaume Mora (Hospital de Sant Joan de Deu, Barcelona, Spain). All culture media and reagents were from Invitrogen (GIBCO, Invitrogen SA, Barcelona, Spain). Cells were seeded at the density of 3 to $4 \times 10^{3}$ cells $/ \mathrm{cm}^{2}$, and drug treatment was initiated on the next day.

The MMP-9 inhibitors, inhibitor A (MMP-2/MMP-9 Inhibitor II 444249) and inhibitor B (MMP-9/MMP-13 Inhibitor I 444252), and the broad MMP inhibitor GM6001 were obtained from Calbiochem (Darmstadt, Germany). Stock solutions were prepared in dimethyl sulfoxide $0.5 \%$ in the final concentration), and concentration-response curves were studied. In each experiment, control cells $(0 \mu \mathrm{mol} / \mathrm{L}$ inhibitor) were exposed to the vehicle for the same time. Human recombinant TGF- $\alpha$ (Calbiochem) was dissolved in $10 \mathrm{mmol} / \mathrm{L}$ acetic acid and then PBS to yield a neutral $\mathrm{pH}$. The day after seeding cells were exposed to TGF- $\alpha$ (10 $\mathrm{ng} / \mathrm{ml})$, and studies were performed at different time points ranging from 1 to 6 days. In some experiments the tyrosine kinase activity of EGFR was inhibited with $10 \mu \mathrm{mol} / \mathrm{L}$ 4,5dianilinophthalimide (RBI, Köln, Germany).

\section{Primary Cultures of Rat Macrophages and Treatments}

Rat macrophages were obtained from the rat bone marrow, and primary cultures were prepared as described previously. ${ }^{22}$ Adult Sprague-Dawley rats (320-350 g b.wt.) were obtained from Charles River Laboratories (Lyon, France). Rats were killed by decapitation, and both femurs were dissected. Animal work was performed in agreement with our local regulations and in compliance with the Directives of the European Community. The end of the bones was cut off, and the marrow tissue was elicited by irrigation with culture medium (Dulbecco's modified Eagle's medium, Lonza/Bio-Whittaker, Basel, Switzer- land). Cells were resuspended by vigorous pipetting and washed once with Dulbecco's modified Eagle's medium. Then cells were seeded into Petri dishes of 150-mm diameter at a density of $10^{7}$ cells per dish. A homogeneous population of macrophages was obtained after 6 days in culture. Cells were grown with medium supplemented with $10 \%$ fetal bovine serum and 30\% of L-cell conditioned medium. In an attempt to increase the rate of cell division, macrophages were starved of L-cell conditioned medium for 18 hours (LO) and, after this period, the medium was added again for 6 hours (L1), 15 hours (L2), 20 hours (L3), 23 hours (L4), or 24 hours (L5).

\section{Silencing MMP-9 Expression}

Expression of MMP-9 was silenced with a small interfering RNA (siRNA) sequence against rat MMP-9 (ON-TARGETplus SMARTpool siRNA sequences, Dharmacon, Thermo Fisher Scientific, Cultek SL, Madrid, Spain). A nontargeting siRNA (D-001810-01, Dharmacon) was used as a negative control (ns-siRNA). siRNAs were transfected into macrophages by electroporation, as reported previously. ${ }^{22}$ In brief, the cells were collected and washed twice with Dulbecco's modified Eagle's medium and then resuspended at a final concentration of $10^{7}$ cells $/ \mathrm{ml}$. Macrophages (400 $\mu$ l) were mixed with $1 \mu \mathrm{mol} / \mathrm{L}$ siRNA in 4-mm gap cuvettes (Bio-Rad Laboratories, Hercules, CA) and placed on ice for 20 minutes. Electroporation was performed at $100 \mu \mathrm{F}, 300 \mathrm{~V}, 13 \Omega(\cong 27 \mathrm{~ms})$ with an electroporator (Bio-Rad Laboratories). Then the samples were placed on ice for 10 minutes before reconstitution in Dulbecco's modified Eagle's medium supplemented with $10 \%$ fetal bovine serum and $30 \%$ of L-cell conditioned medium. Subsequent assays were performed 24 hours after transfection.

SK-N-BE-2C cells were transfected with human MMP-9 siRNA using Lipofectamine 2000 (Invitrogen) as the vehicle, according to the manufacturer's protocol. For the transfection of SH-SY5Y cells we used electroporation because we did not achieve a good silencing effect with lipid carriers. The following siRNA duplex sequence was used for human MMP-9 knockdown: GCGGAGAUUGGGAACCAGCUGUAUU (Stealth RNAi, MMP9HSS106625, Invitrogen, Barcelona, Spain). A nontargeting RNAi was used as a control (Stealth RNAi Negative Control Duplex, 12935-400, Invitrogen). In brief, 2 days after seeding, the transfection was performed in OPTIMEM-minimal essential medium (Invitrogen) with a final siRNA concentration of $120 \mathrm{nmol} / \mathrm{L}$. The knockdown efficiencies of RNAi were confirmed 3 days later by determining the decreases in the level of human MMP-9 expression by RT-PCR using the primers, Hmmp9(+) GCTCACCTTCACTCGCGTG and Hmmp9(-) CGCGACACCAAACTGGATG, and the control primers for human18S ribosomal RNA, H18s(+) GCGAAAGCATTTGCCAAGAA and H18s(-) CATCACAGACCTGTTATTGC. After 2 and 3 days of treatment, cell growth was evaluated with the 3-(4,5-dimethylthiazol-2yl)-2,5-diphenyl tetrazolium bromide (MTT) assay and the ratio between the two MTT values was calculated to assess cell growth per 24 hours under the different experimental conditions. 


\section{Immunocytochemistry}

For studies of immunocytochemistry, cells were cultured in eight-well plastic chamber slides (NUNC, Roskilde, Denmark). Cells were fixed with cold methanol for 10 minutes, washed three times with PBS, and incubated for 1 hour with the blocking solution containing 15\% normal goat or donkey serum. The primary antibodies were three different monoclonal antibodies against MMP-9 (mouse antibodies MAB13421, diluted 1:50 from Chemicon International, Pacisa-Giralt, Barcelona, Spain; and AB10, diluted 1:50, from Oncogene, and rabbit antibody ab76003, diluted 1:500, from Abcam, Inc., Cambridge, MA), and a mouse monoclonal antibody against $\beta$-tubulin (diluted 1:50, Boehringer Mannheim, Germany). Incubation was performed overnight at $4^{\circ} \mathrm{C}$ in the presence of $1 \%$ normal goat or donkey serum, followed by either a red fluorescent cyanine (Cy3)-labeled anti-mouse secondary antibody made in donkey (Jackson ImmunoResearch Laboratories, West Grove, PA), diluted 1:200, or a green fluorescent fluorescein isothiocyanate (FITC)-labeled secondary anti-mouse or anti-rabbit antibody (Molecular Probes, Leiden, The Netherlands), diluted 1:1000, or a red fluorescent Tetramethylrhodamine isothiocyanate (TRITC)-labeled secondary anti-rabbit antibody (Sigma-Aldrich, Alcobendas, Madrid, Spain) diluted 1:200. The secondary antibody was incubated for 1 hour at room temperature in the presence of $1 \%$ normal donkey or goat serum. After this, cells were washed with PBS, mounted with a mounting media (Mowiol, Calbiochem, San Diego, CA), and fluorescence was examined under a $40 \times$ objective in an optical microscope (Eclipse E1000M/E1000, Nikon, IZASA, Barcelona, Spain) equipped with a super high-pressure mercury lamp power supply (HB-10103AF, Nikon). Red fluorescence from Cy3 fluorochrome (550 nm excitation and $570 \mathrm{~nm}$ emision) and green FITC fluorescence (495 nm excitation and $519 \mathrm{~nm}$ emission) were observed using the corresponding filter cubes G-2A and B-2A (Nikon), respectively. Double staining was examined with the confocal microscope (TCS-NT, Leica, Wetzlar, Germany) under a $63 \times$ objective (PL APO $63 \times / 1.40$ oil). The confocal microscope was equipped with an argon-krypton laser and was used at $568 \mathrm{~nm}$ (DD488/568) excitation with a LP590 emission filter for red light, and at $510 \mathrm{~nm}$ (RSP510) excitation with a BP530/30 emission filter for green light.

To visualize DNA, cells were counterstained with 5 $\mu \mathrm{g} / \mathrm{ml}$ bisbenzimide (Hoechst 33258 dye, Sigma-Aldrich) in PBS for 20 minutes, which binds DNA and produces UV light. Hoechst 33258 (359 nm excitation and $461 \mathrm{~nm}$ emission) staining was examined under the fluorescence microscope (Eclipse E1000M/E1000) with the corresponding filter cube (UV-2A) using the 20x and 40x objectives. Triple color staining (Cy3, FITC, and UV) was examined with a $63 \times$ magnification objective $(\mathrm{HCX} \mathrm{PL}$ APO $63 \times / 1.32$ oil PH3 CS) in a confocal microscope (SP2, Leica) equipped with UV excitation (argon laser-UV $351 / 364 \mathrm{~nm}$ ), and the lasers used for green and red lights were argon (488 nm) and helium-neon $(543 \mathrm{~nm})$, respectively. Images were acquired with the corresponding Leica confocal software. Figures composed of several images were prepared with Adobe Photoshop software.
In a few experiments, we tested MMP-9 immunoreactivity in cultured mouse fibroblasts kindly provided by Dr. Joan Serratosa.

\section{Flow Cytometry Analyses}

The cell cycle was studied by measuring DNA cell content after incubation of fresh cells with $0.1 \%$ Triton $\mathrm{X}-100$, $0.2 \mathrm{mg} / \mathrm{ml}$ RNase, and $25 \mu \mathrm{g} / \mathrm{ml}$ propidium iodide (PI) for 30 minutes. Flow cytometry was performed with an Epics XL flow cytometer (Coulter Corporation, Hialeah, FL). The instrument was set up with the standard configuration: excitation of the sample was done using a standard 488 $\mathrm{nm}$ air-cooled argon ion laser at $15 \mathrm{~mW}$ power. Forward scatter, side scatter, red $(620 \mathrm{~nm})$ fluorescence for PI was acquired. Red fluorescence was collected with a 645 dichroic long filter and a 675 band pass filter. Optical alignment was based on optimized signal from 10-nm fluorescent beads (Immunocheck, Epics Division, Aberystwyth, Wales, UK). Time was used as a control of the stability of the instrument. Red fluorescence was projected on a 1024 monoparametrical histogram and DNA analysis (ploidy analysis) was done using Multicycle software (Phoenix Flow Systems, San Diego, CA). Aggregates were excluded, gating single cells by their area versus peak fluorescence signal.

MMP-9 content along the cell cycle was analyzed by antibody staining. Cells were harvested by mild trypsinization $(0.01 \%$ trypsin in PBS with $0.02 \%$ EDTA), washed with PBS, and resuspended in $0.5 \mathrm{ml}$ of PBS. Methanol at $-20^{\circ} \mathrm{C}$ was added drop to drop up to a volume of $5 \mathrm{ml}$. After 4 hours of fixation, cells were permeabilized with $2.5 \%$ Triton X-100 for 5 minutes, preincubated with $1 \%$ bovine serum albumin in PBS, and incubated overnight at $4^{\circ} \mathrm{C}$ with a mouse monoclonal antibody against MMP-9 (MAB 13421, diluted 1:50, Chemicon International, Temecula, CA) in a roller shaking in the presence of $1 \%$ BSA. Cells were washed twice with PBS and incubated with the secondary antibody FITC conjugated (1:100) for 1 hour. Cells were counterstained with $\mathrm{Pl}$ as detailed above, and flow cytometry was performed. Green (525 nmol/L) fluorescence for FITC-conjugated antibody was collected with a 550 dichroic long filter and a 525 band pass filter. Quantification of MMP-9 stain (FITC) intensity at distinct phases of the cell cycle (PI staining) was done simultaneously on FITC/immunoprecipitation dot plots.

\section{Assays of Cell Growth and Cytotoxicity}

Changes in cell growth were determined by the reduction of the tetrazolium salt MTT (Sigma-Aldrich) to the colored product formazan, a general measure of cellular oxidative capacity. MTT was dissolved at a concentration of 5 $\mathrm{mg} / \mathrm{ml}$ in PBS, sterilized by filtration, and stored for up to 1 month at $4^{\circ} \mathrm{C}$ protected from light and tightly capped. This mixture was added to the 96-well cell culture plates at a final concentration of $0.5 \mathrm{mg} / \mathrm{ml}$, and the plates were returned to an incubator. Two hours later, incubation was terminated by adding extraction solution (100 $\mu \mathrm{l} / \mathrm{well})$ 
containing $20 \%$ SDS in $\mathrm{N}, \mathrm{N}$-dimethyl formamide/water (1:1), pH 4.7. The plates were tightly wrapped with Parafilm to avoid evaporation and incubated overnight at $37^{\circ} \mathrm{C}$. Optical density was measured at $570 \mathrm{~nm}$ (reference wavelength $630 \mathrm{~nm}$ ), using the extraction buffer solution as a blank, in a plate reader (iEMS Reader MF, Labsystems, Helsinki, Findland).

Cell number counting was determined in parallel experiments using the trypan blue dye exclusion assay to check the viability of the cells. Cultures in 12-well plates were washed with PBS and mildly trypsinized in the presence of $0.02 \%$ EDTA. The reaction was stopped by adding 5\% fetal bovine serum, and the cells were washed and resuspended in $0.5 \mathrm{ml}$ of PBS. One-half milliliter of $0.4 \%$ trypan blue solution (w/v) was added to each sample, mixed, and allowed to stand for 5 to 15 minutes. Viable (nonstained) and nonviable (stained) cells were counted in a hemocytometer.

The presence of mitosis was studied in 24-well plates after nuclear staining with Hoechst 33258 dye. Staining was observed under an inverted microscope (IX50/IX70, Olympus, Tokyo, Japan) equipped with an inverted reflected light fluorescence observation attachment (IXFLA) containing a mercury lamp and appropriate filter cube (U-MWU, BP 330 to $385 \mathrm{~nm}$ excitation) and barrier filter (BA420) for UV light. Mitotic figures were counted and were related to the number of cells in each microscopic field using the $20 \times$ objective.

PI staining was used to identify the presence of dead cells in fresh (nonfixed) cultures. Pl enters cells with damaged membranes and greatly increases their fluorescence by binding to nucleic acids. PI was added to the cultures at a final concentration of $15 \mu \mathrm{g} / \mathrm{ml}$ and was incubated for 30 minutes, and then media with PI was washed with warm PBS and the cultures were immediately observed under the inverted microscope (IX50/IX70, Olympus), as above, using an appropriate filter cube (U-MNG, BP 530 to $550 \mathrm{~nm}$ excitation) and barrier filter (BA590).

\section{Gelatinase Extraction and Gel Zymography}

Culture medium was separated from the cells, which were trypsinized and washed with PBS, and the cellular pellets were subjected to detergent extraction and purification of gelatinolytic activity following the method described by Zhang and Gottschall, ${ }^{23}$ with modifications as reported.24-26 In brief, samples were homogenized in lysis buffer (250 $\mu$ l per 2 to $4100-m m$ dishes) containing detergents (Brij-35 and 1\% Triton X-100). All reagents, unless otherwise stated, were from Sigma-Aldrich. Homogenates were centrifuged at $12,000 \times g$ for 5 minutes, and an aliquot of the supernatant was taken as the protein fraction for Western blot analysis. The rest of the supernatant was incubated with gelatin-Sepharose 4B (25 $\mu$ l, Amersham Biosciences Europe $\mathrm{GmbH}$, Frigurg, Germany) for 1 hour at $4^{\circ} \mathrm{C}$. After washing, MMPs were separated from the Sepharose pellet by incubation with $30 \mu \mathrm{l}$ of elution buffer containing $10 \%$ dimethyl sulfoxide for 30 minutes at $4^{\circ} \mathrm{C}$. Gel zymography was performed with samples of extracted cells (equivalent to $50 \mu \mathrm{g}$ of protein in the supernatant after homogenization). Gels containing $10 \%$ acrylamide and porcine gelatin $(1 \mathrm{mg} / \mathrm{ml})$ were prepared, and electrophoresis followed by gel staining was performed, as reported. ${ }^{23}$ A mixture of MMP-9 and MMP-2 containing gelatinase (CC073, Chemicon International) was used as a standard.

MMP activity was inhibited by using either the broadspectrum MMP inhibitor GM6001 (10 $\mu \mathrm{mol} / \mathrm{L})$ or EDTA $(10 \mathrm{mmol} / \mathrm{L})$ that was applied to the incubation medium of the zymography gels after electrophoresis. The inhibitor was prepared in dimethyl sulfoxide at a concentration of $10 \mathrm{mmol} / \mathrm{L}$ and then diluted in the incubation buffer to the working concentration.

\section{Real-Time RT-PCR}

Expression of MMP-9 mRNA in cultured macrophages was studied by Real-Time RT-PCR. For cDNA synthesis, $1 \mu \mathrm{g}$ of RNA was subjected to transcription using Moloney murine leukemia virus reverse transcriptase $\mathrm{RNase} H$ minus point mutant, oligo(dt)15 primer and PCR nucleotide mix (Promega, Madison MT). Then real time-PCR was performed using a kit (Bio-Rad Laboratories). The final volume was $15 \mu \mathrm{l}$ of SYBR Green Master Mix. The primers were GTATTGGAAGTTCTCGAATCAC for MMP-9 $(+)$ and CAAGTCGAATTTCCAGATACG for MMP-9 $(-)$. Quantification was performed with rat hypoxanthine guanine phosphoribosyl transferase 1 (HPRT1) gene as the reference, using the following primers: CTGAAGAGCTACTGTAATGACCA for HPRT1 (+) and CCTGTATCCAACACTTCGAG for HPRT1 ( $)$.

\section{Western Blotting}

Samples from the protein fraction were subjected to Western blot analysis, as reported previously, ${ }^{24}$ with monoclonal antibodies against MMP-9 (mouse monoclonal antibody, diluted 1:150, MAB13420 from Chemicon International; and a rabbit monoclonal antibody, diluted 1:5000, ab76003 from Abcam). A mouse monoclonal antibody against $\beta$-tubulin (Boehringer Mannheim, Mannheim, Germany), diluted 1:5000, was used to control protein gel loading. Secondary antibody was peroxidaselinked anti-mouse Ig (Amersham, Madrid, Spain), diluted 1:2000. The reaction was developed with a chemiluminescence method. Gels were scanned with a Kodak camera (DC-120) and analyzed with appropriate software to determine band intensity (Kds1D, Eastman Kodak, Rochester, NY).

\section{In Situ Gelatin Zymography}

Cells were cultured in eight-well plastic slides and incubated with $10 \mu \mathrm{g} / \mathrm{ml}$ FITC-labeled DQ-gelatin (Molecular Probes, Eugene, OR) for 1 hour at room temperature in a humidified chamber. Then sections were washed with PBS and counterstained with Hoechst 33258 dye. Green FITC fluorescence indicative of gelatinase activity was observed under a $20 \times$ objective of the fluorescence microscope (Eclipse E1000M/E1000) with the corre- 
sponding filter cube (B-2A), as stated above for immunostaining. The same fields were observed under the UV light to visualize DNA staining with Hoechst 33258 dye using the appropriate filter cube (UV-2A, Nikon). In situ zymography was performed in the presence or absence of the broad spectrum MMP inhibitor 1,10-phenanthroline monohydrate $(0.2 \mathrm{mmol} / \mathrm{L})$.

\section{Treatment with Recombinant MMP-9}

Macrophages and SK-N-BE-2C cells were treated with 50 or $100 \mathrm{ng} / \mathrm{ml}$ recombinant human MMP-9 (rMMP-9) (ab39308, Abcam). Because serum contains MMP-9, this experiment was performed after gelatinases were removed from the serum by incubation overnight at $4^{\circ} \mathrm{C}$ with gelatin-Sepharose 4B beads (diluted 1:10, Amersham Biosciences Europe $\mathrm{GmbH}$ ) that was previously washed twice to remove ethanol. After incubation, beads were removed from the sample by centrifugation for 5 minutes at $1000 \times g$. The successful extraction of MMP-9 from serum was verified by Western blotting. The medium of the cells was changed to medium containing either normal serum or gelatinase-free serum, in the presence or absence of added rMMP-9. Before the latter incubation, macrophages were deprived of L-cells for 16 hours to stimulate cell growth at addition of the new medium containing L-cells and the various serum conditions described above. One day after exposure of macrophages and neuroblastoma cells to normal serum or gelatinasefree serum (containing or not containing additional rMMP9), cell growth was assessed with the MTT assay.

\section{Statistical Analyses}

Two groups were compared with Student's t-test after testing for normality. Multiple group comparisons were performed by one-way analysis of variance followed by Dunnett's multiple comparison test or Bonferroni test comparisons between the two groups. Nonlinear regression analysis was performed using GraphPad Prism software. Goodness of fit was assessed by $R^{2}$. Linear regression analysis was performed using the same software.

\section{Results}

\section{MMP-9 in Mitotic Cells}

The cellular distribution of MMP-9 immunoreactivity and gelatinase activity was studied in SH-SY5Y cells (Figure 1, A-K). Faint MMP-9 staining was found in the cytoplasm and cell extensions (Figure 1B), and very intense staining
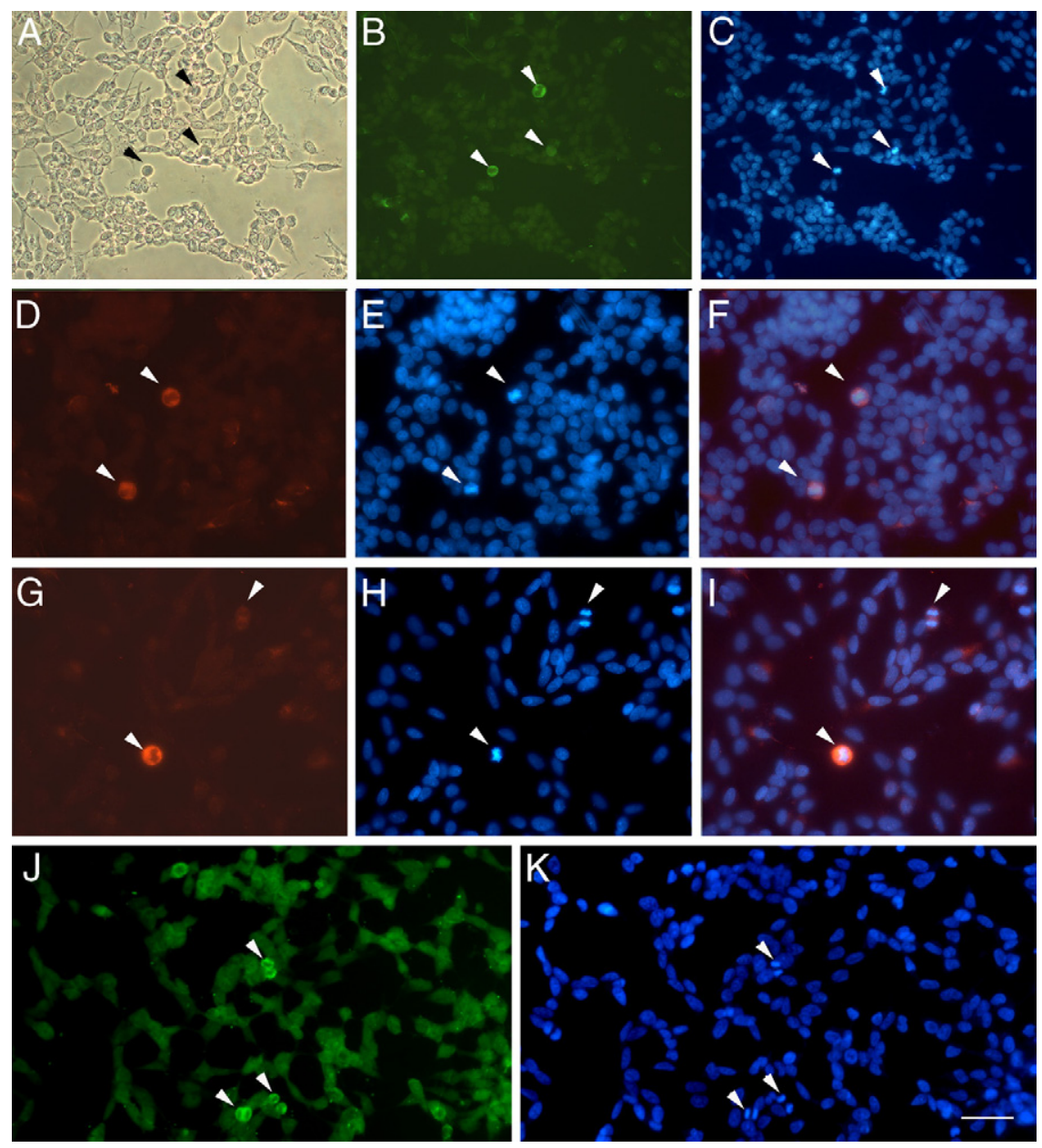

Figure 1. High expression of MMP-9 immunoreactivity in cells undergoing cell division. A Phase-contrast image of SH-SY5Y neuroblastoma cells using the optical microscope. B: MMP-9 immunofluorescent staining with a mouse monoclonal antibody (Chemicon International). Arrowheads point to strongly MMP9-immunoreactive cells (green). C: Cells undergoing mitosis as revealed with Hoechst 33258 dye (blue), which stains the dividing condensed chromosomes (arrowheads) bright blue. D-F: MMP-9 immunostaining (D, red, arrowheads) and Hoechst 33258 staining (E, blue), showing in the merged image (F) that MMP-9 immunoreactivity (red) surrounds the DNA (bright blue), in cells at metaphase (arrowheads). G-I: MMP-9 staining (G, red, arrowheads) and corresponding Hoechst 33258-stained mitotic cells (H, bright blue, arrowheads) at metaphase (bottom left) and anaphase (top right), again showing correspondence in the merged image (I). $\mathbf{J}$ : In situ gelatin zymography after incubation of cultured cells with fluorescein-labeled gelatin (see Materials and Methods). K: Green fluorescent staining reveals stronger gelatinase activity in cells undergoing division (arrowheads), as revealed with Hoechst 33258 dye (bright blue, arrowheads). Strong gelatinase activity is seen within mitotic cells in the area surrounding the chromosomes. Scale bars A-C $=50 \mu \mathrm{m} ; \mathbf{D}-\mathbf{K}=$ $25 \mu \mathrm{m}$. 
was found in cells undergoing mitosis (arrows in Figure 1). This was confirmed with double staining with bisbenzimide (Hoechst 33258 dye), which binds DNA and produces UV light showing brighter staining in the condensed DNA of dividing cells (arrows in Figure 1C). In mitotic cells (Figure 1, D-I), MMP-9 staining was distributed within the cell, excluding the area of the chromosomes. The specificity of the immunoreaction was tested by using two different monoclonal antibodies against MMP-9 (see Materials and Methods) with two different fluorescent secondary anti-mouse antibodies (one labeled in green with FITC-fluorochrome [Figure 1B] and the other labeled in red with Cy3-fluorochrome [Figure 1, $\mathrm{D}$ and $\mathrm{G}]$ ) and by omitting the primary antibody but not the secondary fluorescent antibody, which gave no signal.

To validate these findings, MMP-9 immunostaining was performed with a mouse monoclonal antibody against MMP-9 followed by a FITC-labeled anti-mouse secondary antibody, combined with propidium iodide staining, and the cells were analyzed by flow cytometry. FITC immunofluorescence of cells in the $S, G_{2}$, or $M$ phases was $5.11 \pm 0.05$ fluorescence units, a value that was higher ( $t$ test $P<0.0005, n=4$ ) than that of cells at the $\mathrm{G}_{1}$ phase (3.82 \pm 0.18 fluorescence units). These results showed that MMP-9 staining was enhanced in cells undergoing division.

In situ gelatin zymography using fluorescein-labeled gelatin showed some low gelatinase activity in the cells and a notably stronger activity in mitotic cells (Figure $1 \mathrm{~J}$ ), as revealed with double staining with Hoechst 33258 dye (Figure $1 \mathrm{~K}$ ). Gelatinase activity in mitotic cells was detected within the cell body excluding the chromosomal area (Figure 1, J and $\mathrm{K}$ ).

\section{Dynamic Distribution of MMP-9 Immunostaining in Relation to Microtubules during Mitosis}

MMP-9 immunoreactivity was very strong at prophase (Figure 2A). To examine the cellular distribution of MMP-9 staining in relation to that of microtubules, we performed double staining against MMP-9 and $\beta$-tubulin (Figure 2). MMP-9 immunoreactivity was detected surrounding the mitotic spindle at the different stages of mitosis. At prometaphase the nuclear envelope fenestrates, allowing the microtubules entering the nucleus and forming the mitotic spindle (see spring-like lattice structure labeled in green in the cell at the top of Figure 2C). A thick wall of MMP-9 immunostaining was distributed beyond the spindle though prometaphase and metaphase (Figure 2C). At early anaphase, when partition of the two sister chromatids is initiated and before the two centrioles also begin to separate toward opposite sides of the cell, the confocal microscopy projection image (Figure 2D) showed MMP-9 immunostaining mainly distributed between the two poles of the mitotic spindle. More detailed examination of different $0.5-\mu \mathrm{m}$ sections of the cell with confocal microscopy (Figure 2, E-I) showed MMP-9 staining in a central location between the two poles of the spindle. During cytokinesis (Figure 2J), by which segmentation takes place, a ring of MMP-9 surrounded two clearly separated zones containing one centriole each, which were interconnected through the microtubules of the spindle. At this period, the segmentation sulk (arrow in Figure 2J) is formed, allowing cytoplasm division and further separation of the two daughter cells. Omission of the primary antibody against MMP-9 but in the presence of the secondary Cy3-labeled antibody, followed by reaction with the primary anti- $\beta$-tubulin antibody and then the FITClabeled secondary antibody, produced no red reaction, as only green staining showing $\beta$-tubulin immunoreactivity became apparent (Figure 2B). These results indicate that MMP-9 might be involved in the rearrangement of the nuclear matrix, cell structures, and/or cytoplasm to allow cell division once DNA was duplicated in neuroblastoma. In addition, we examined whether this particular distribution of MMP-9 immunoreactivity detected in SH-SY5Y cells was also observed in a different cell type. We performed MMP-9 immunocytochemical analysis in mouse fibroblasts and observed a higher intensity of staining in mitotic cells (Figure 2L).

Images to better illustrate the presence of MMP-9 immunoreactivity during the process of cell division are shown in Figures 3 and 4, where MMP-9 staining (red) is combined with $\beta$-tubulin staining (green) and Hoechst staining (blue). Neuroblastoma cells showed MMP-9 immunoreactivity surrounding the DNA during the early phases of mitosis from prophase to metaphase, before the two sister chromatids begin to separate (Figures 3, A-C and D-F, and 4, A-D). However, MMP-9 immunoreactivity became apparent in the center of the cell at the time that the two chromatids began to separate at anaphase (Figures 3, G-I, and 4, E-L). At telophase, when the two sets of chromosomes reach the poles of the spindle and become completely partitioned (Figure 3, $J-L)$, MMP-9 immunoreactivity was located within the segmentation sulk surrounding the contractile microtubule ring. Then, at cytokinesis immunoreactivity surrounded the daughter cells (Figure 3, M-O).

We also examined MMP-9 immunoreactivity in the NMyc-amplified neuroblastoma cell line, SK-N-BE-2C and found a pattern of MMP-9 expression in mitotic cells similar to that in SH-SY5Y cells (Supplemental Figure 1, see $h$ ttp://ajp.amjpathol.org).

\section{MMP-9 Inhibitors Caused Cell Cycle Alterations}

The cell cycle was examined by flow cytometry using propidium iodide staining after incubation of the cells for 1 or 3 days in the presence or absence of MMP inhibitors. Inhibitor A is specific for MMP-9 and MMP-2, whereas inhibitor B was designed to target MMP-9 and MMP-13. Overall the inhibitors increased the percentage of cells in the $S$ phase, whereas they reduced the percentage of cells in the $\mathrm{G}_{1}$ phase (Figure 5) ( $n=4$ to 9 samples from at least two independent experiments). For inhibitor $A$ (Figure 5A), the most marked effects were detected at day 1. At this time, the percentage of cells in the $S$ phase significantly (one-way analysis of variance) increased in relation to controls by $19 \%(P<0.05)$ and $38 \%(P<$ 

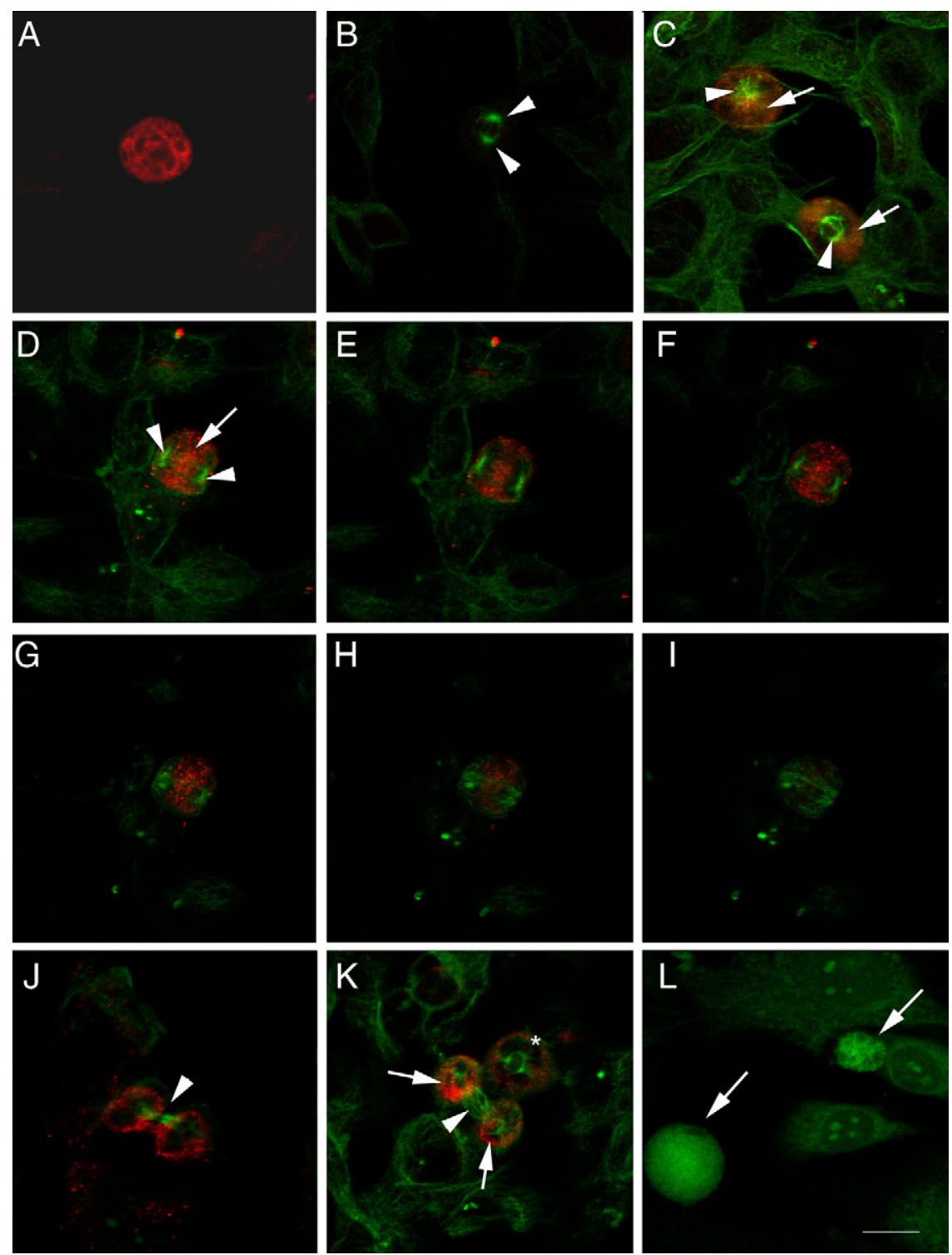
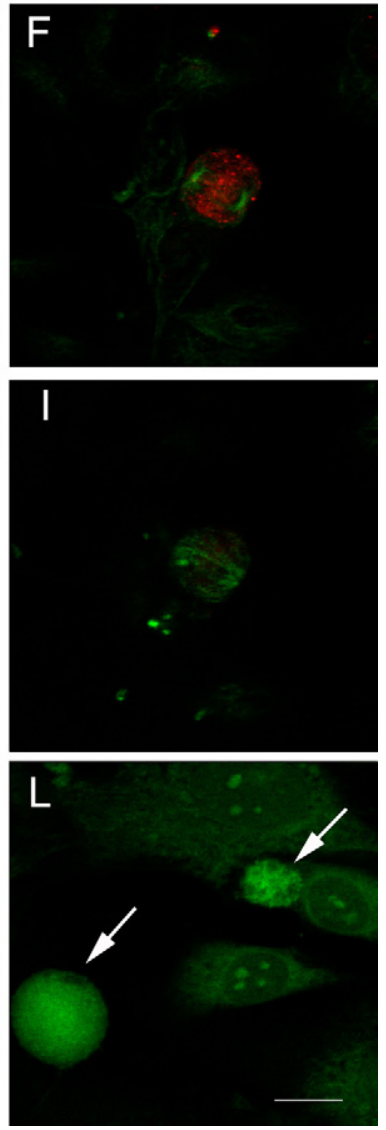

Figure 2. MMP-9 immunoreactivity and the mitotic spindle labeled with $\beta$-tubulin. Confocal microscope images showing MMP-9 immunoreactivity (red in $\mathbf{A}-\mathbf{K}$ and green in $\mathbf{L}$ ) and/o $\beta$-tubulin (green in $\mathbf{A}-\mathbf{K}$ ). The monoclonal antibody against MMP-9 was either from Oncogene (A) or Chemicon International (B-L). Cells in A-K are SH-SY5Y neuroblastoma cells, whereas cells in $\mathbf{L}$ are mouse fibroblasts. A: Single immunocytochemistry against MMP-9 shows strong MMP-9 immunostaining in a cell at prophase. $\mathbf{B}$ Negative control for double immunocytochemistry against MMP-9 and $\beta$-tubulin, in which the primary antibody against MMP-9 was omitted Arrows show the two poles of the mitotic spindle in a dividing cell. C: Cells at prophase (top) and metaphase (bottom) showing MMP-9 (red, arrows) located behind the centrosomes (green, arrowheads). D-I: Cell at anaphase showing MMP-9 (red, arrow) between the two poles (arrowheads) of the mitotic spindle (green). D: Projection image. E-I: Sequential $0.5-\mu \mathrm{m}$ sections through the cell. $\mathbf{J}$ : Cell at cytokinesis showing the two separated daughter cells surrounded by MMP-9 immunoreactivity and connected by the rest of the spindle microtubules at the segmentation sulk (arrow). K: Cell at prometaphase (asterisk) and cell at cytokinesis showing two clearly distinguished MMP-9-immunostained areas (red, arrows) surrounding the two daughter cells, which are connected through the microtubules of the spindle (arrowhead). L: MMP-9 staining (green) is stronger in dividing (arrows) than in resting fibroblasts. Arrows (C-K) point to zones of MMP-9-immunoreactivity, and arrowheads point to the tubulin-positive mitotic spindle in dividing cells Arrows in $\mathbf{L}$ point to MMP-9-positive cells. Scale bar $=15 \mu \mathrm{m}$.
0.001 ) at the doses of 15 and $20 \mu \mathrm{mol} / \mathrm{L}$, respectively. Significant reductions in the percentage of cells in the $G_{1}$ phase were detected related to controls, i.e., $-10 \%(P<$ $0.05)$ and $-17 \%(P<0.001)$ at the doses of 15 and 20 $\mu \mathrm{mol} / \mathrm{L}$, respectively. For inhibitor B (Figure $5 \mathrm{~B}$ ), the most marked effects were seen at day 3 when an increase of approximately $20 \%(P<0.001)$ in the percentage of cells in the $S$ phase was detected at the doses of 10 and 15 $\mu \mathrm{mol} / \mathrm{L}$, together with an increase of approximately $16 \%$ $(P<0.05$ at the dose of $10 \mu \mathrm{mol} / \mathrm{L})$ in the percentage of cells in the $G_{2}$ phase. This inhibitor significantly reduced the percentage of cells in the $\mathrm{G}_{1}$ phase by approximately $-5 \%(P<0.001)$. Examples of cycle analysis data are shown in Figure 5C for a control and in Figure 5D for a cell culture treated with MMP inhibitor A. These results indicate that the MMP inhibitors reduced the ability of cells to divide after DNA was synthesized during the $S$ phase, and cell proliferation was subsequently impaired.

\section{MMP Inhibitors Reduced Cell Growth}

We seeded the cells, let them grow for 2 days, and then incubated the cultures (time 0 ) in the presence or absence of different inhibitor concentrations (5 to $30 \mu \mathrm{mol} / \mathrm{L}$ inhibitor $A$ and 1 to $35 \mu \mathrm{mol} / \mathrm{L}$ inhibitor B). Gel zymography with cellular extracts showed the presence of intrinsic gelatinases in SH-SY5Y cells (Figure 6A). In control cells, a faint MMP-9 band was observed together with a more intense band corresponding to MMP-2. MMP inhibitor A targeting MMP-9 and MMP-2 reduced both gelatinase bands, whereas inhibitor B mainly affected MMP-9 (Figure 6B). Gelatinase bands were no longer seen when zymography gels were exposed to EDTA in the incubation buffer because they require $\mathrm{Ca}^{2+}$ (not shown).

The cell growth and viability MTT assay was performed 3 days after incubation in the presence or absence of the inhibitors. The inhibitors significantly prevented cell 

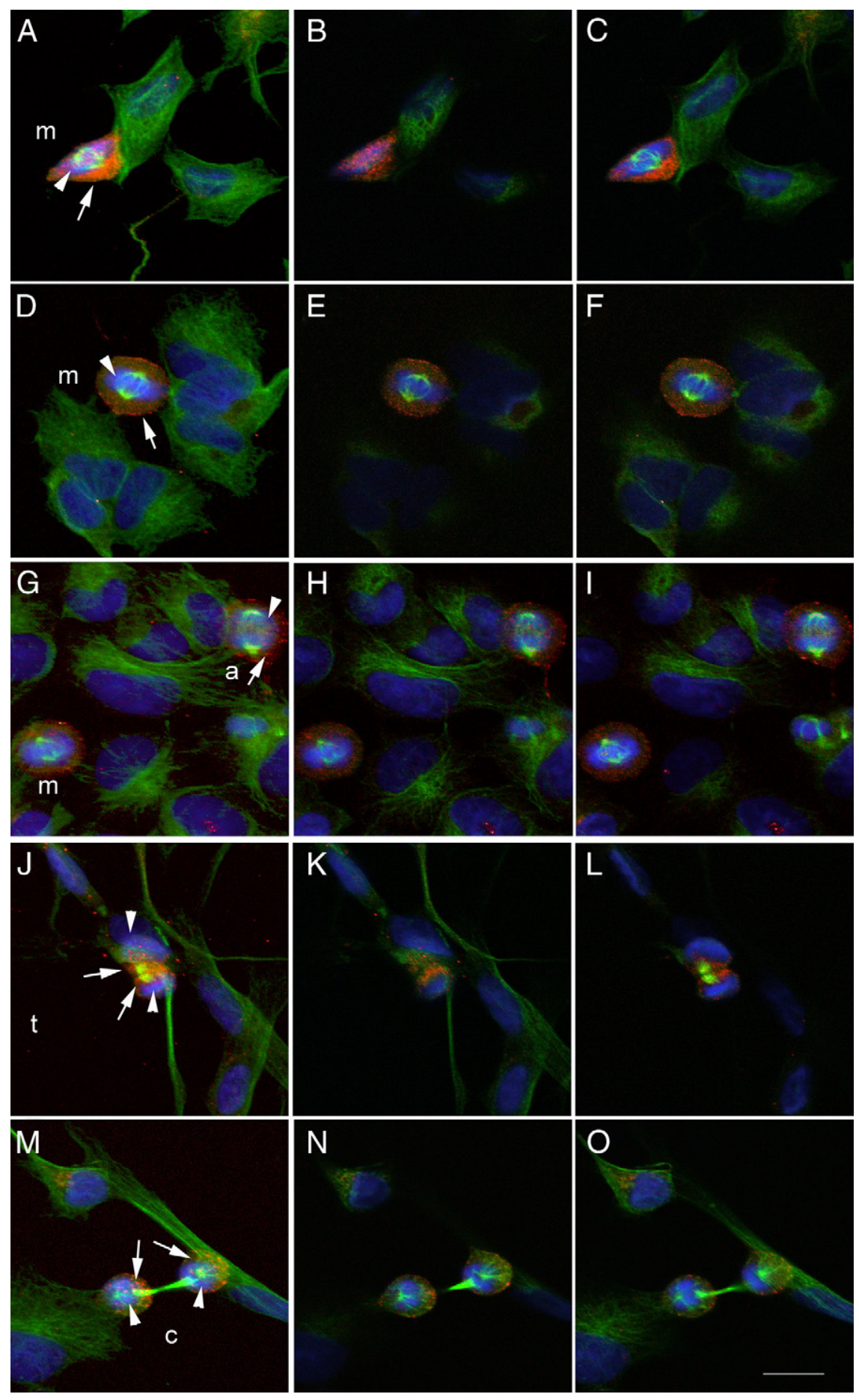

Figure 3. MMP-9 immunoreactivity through the different mitotic stages. Staining with antibodies against MMP-9 (Chemicon International) (red) and $\beta$-tubulin (green) and Hoechst DNA staining (blue). A-E: Cells at different phases of mitosis. The first picture of each row (left) shows the maximal projection confocal image, whereas the two pictures on the right of each row correspond to $0.5-\mu \mathrm{m}$-thick sections of the same cell, respectively. A-C and D-F: Cells at metaphase (m) showing DNA condensation (blue, arrowhead) and centrosomes (green), as labeled with $\beta$-tubulin, are surrounded by intense red staining against MMP-9 (arrow). G-I: Two mitotic cells, one at metaphase $(\mathrm{m})$ (bottom left) and one at anaphase (a) (top right). The cell at anaphase, characterized by a greater separation between the poles of the spindle and chromatid partition (arrowheads), show MMP-9 staining (arrow) that is located surrounding the DNA and also between the separating chromatids. J-L: Cell at telophase (t), which exhibits a completed chromatid partition (arrowheads) through the contractile ring, shows MMP-9 staining (arrows) between the two chromatids. M-O: Two daughter cells at cytokinesis (c), which are still connected through the rest of the mitotic spindle or medial corps (green), show MMP-9 staining (arrows) surrounding the chromatids (arrowheads). Arrows point to MMP-9 staining and arrowheads point to DNA. Scale bar $=15 \mu \mathrm{m}$.

growth in a concentration-dependent manner as the MTT values were progressively reduced in relation to the control (Figure 6, C and D). Data were fit to two-phase exponential decay equations $\left(R^{2}=0.86\right.$ for inhibitor $\mathrm{A} ; R^{2}=$ 0.87 for inhibitor B).

We performed the MTT assay at time 0 and at day 3 after incubation in the presence or absence of the inhibitors and determined the MTT values at day 3 as the percent increase in relation to MTT at time 0 (basal) to assess whether inhibitors reduced MTT to values below basal. In control cell cultures (vehicle-treated in the ab- sence of inhibitors), the MTT values increased by $75 \%$ from time 0 to day 3. Exposure to concentrations of inhibitors up to $20 \mu \mathrm{mol} / \mathrm{L}$ for 3 days reduced $(P<0.001)$ the MTT value in relation to that for the controls without affecting cell viability (Figure $7, A$ and B). However, the highest doses (from $20 \mu \mathrm{mol} / \mathrm{L}$ ) reduced $(P<0.001$ ) MTT to values lower than basal MTT at time 0 , thus suggesting that prolonged exposure to the highest concentrations of inhibitors might have some toxic effects in neuroblastoma cells. The numbers of living and dead cells in the cultures were counted by means of the trypan blue dye exclusion 

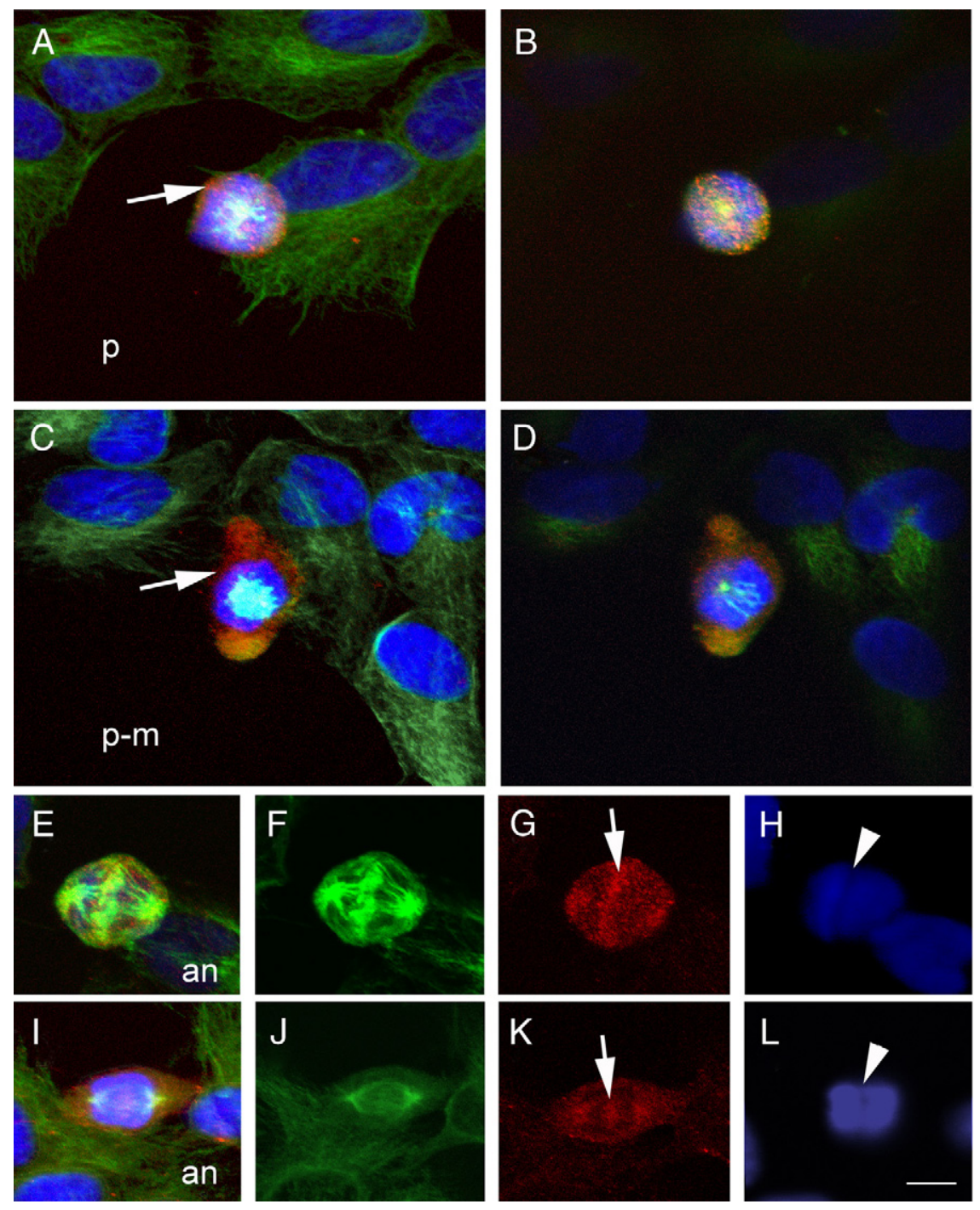

Figure 4. Confocal microscopy images showing details of the subcellular location of MMP-9 immunoreactivity at certain mitotic phases. Staining with antibodies against MMP-9 (Chemicon International) (red) and $\beta$-tubulin (green) and Hoechst DNA staining (blue). A: Projection confocal image of a cell at prophase (p) surrounded by MMP-9-like immunoreactivity (arrow). B: Section $(0.5-\mu \mathrm{m}$-thick) of the cell shown in $\mathbf{A}$. The zone of microtubule (green) depolymerization for centrosome formation is in close proximity to MMP-9 immunoreactivity (red), as is shown by the yellow area in the center of the cell. C: Projection confocal image of a cell at late prophase-prometaphase ( $\mathrm{p}-\mathrm{m})$, showing a thick wall of intense MMP-9 staining (arrow) surrounding the DNA (blue). D: Section $(0.5-\mu \mathrm{m}$ thick) of the cell shown in $\mathbf{C}$, showing the centrosome and forming a mitotic spindle (light blue) on the top of DNA (dark blue). E and $\mathbf{I}$ Images of cells at anaphase (an) (merged image) are composed of corresponding single images of $\beta$-tubulin (F and $\mathbf{J}$, green), MMP-9 immunoreactivity ( $\mathbf{G}$ and $\mathbf{K}$, red), and DNA ( $\mathbf{H}$ and $\mathbf{L}$, blue). E: Cell at anaphase showing that MMP-9 staining is in close proximity to the microtubules (yellow). F: Enlargement of the kinetocore microtubules located between the separating chromatids as marked in $\mathbf{H}$ with an arrowhead. At this stage, MMP-9 staining (arrow in G) is apparent between the separating chromatids $(\mathbf{H})$. I: Cell at anaphase showing increased separation between the poles of the spindle, with acquisition of a fusiform shape and with MMP-9 staining at the migrating opposite poles of the cells. J shows microtubules and $\mathbf{K}$ shows MMP-9 staining (arrow) between the two separating chromatids (shown in $\mathbf{L}$, arrowhead). Arrows point to MMP-9 staining and arrowheads point to DNA. Scale bar $=10 \mu \mathrm{m}$. assay to assess cell death. The number of dead cells (expressed as the percentage of total cell number) was not increased by 3-day exposure to inhibitors (15 and 20 $\mu \mathrm{mol} / \mathrm{L}$ for inhibitor $A$ and 10 and $15 \mu \mathrm{mol} / \mathrm{L}$ for inhibitor B) compared with that in the 3-day vehicle-treated control (Figure 7C). However, the number of living cells was reduced $(P<0.001)$ by approximately $30 \%$ after the 3-day exposure to $20 \mu \mathrm{mol} / \mathrm{L}$ inhibitor $A$ or $15 \mu \mathrm{mol} / \mathrm{L}$ inhibitor B (Figure 7D), despite the fact that cell death was not promoted by these treatments. These results strongly suggest that the inhibitors reduced cell growth at concentrations that caused no toxicity to the cells. This finding was validated in another set of experiments in which cultures were examined using the optical microscope and the fluorescence microscope after PI staining, because no signs of induced cell death were observed (not shown).

We then incubated the cultures with the inhibitors for 2 days instead of 3 days and performed the MTT assay to determine whether a similar effect on cell growth could be observed with shorter exposure times. At 2 days, cell growth was reduced $(20 \%, P<0.001)$ by $30 \mu \mathrm{mol} / \mathrm{L}$ inhibitor A (Supplemental Figure 2A, see http://ajp. amjpathol.org) and $36 \mu \mathrm{mol} / \mathrm{L}$ inhibitor B (Supplemental Figure 2B, see http://ajp.amjpathol.org). Compared with this 2-day exposure, the concentrations needed to cause $20 \%$ MTT reduction with the 3-day exposure were approximately $15 \mu \mathrm{mol} / \mathrm{L}$ inhibitor $A$ and $10 \mu \mathrm{mol} / \mathrm{L}$ inhibitor $B$, and therefore the effect of the inhibitors on cell growth was time-dependent. We also checked that the 2-day exposure did not cause cell death by performing the trypan blue exclusion assay after inhibitor incubation, which showed that cell death was not enhanced by the treatment (Supplemental Figure 2C, see http://ajp. amjpathol.org). Indeed, the mean \pm SEM percentage of dead cells (in relation to total number of cells) was $7.4 \pm$ $2.53 \%$ in controls at time 0 and $13.1 \pm 0.96 \%$ in controls at time 2-days, whereas the corresponding value after 2-day exposure to $30 \mu \mathrm{mol} / \mathrm{L}$ inhibitor A was $5.2 \pm 0 \%$. Again, the trypan blue exclusion assay showed that the number of cells increased by 3.6-fold from 0 to 2 days under control conditions, whereas under exposure to the inhibitor the increase was limited to 1.3-fold (Supplemental Figure 2D, see http://ajp.amjpathol.org). In addition, we 
A

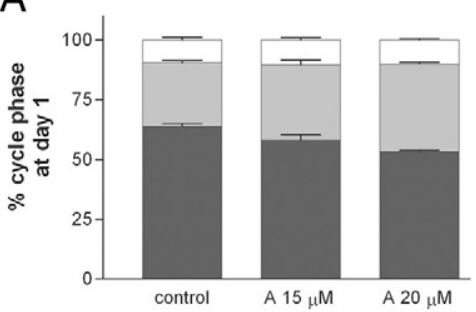

$\square$ G2

C

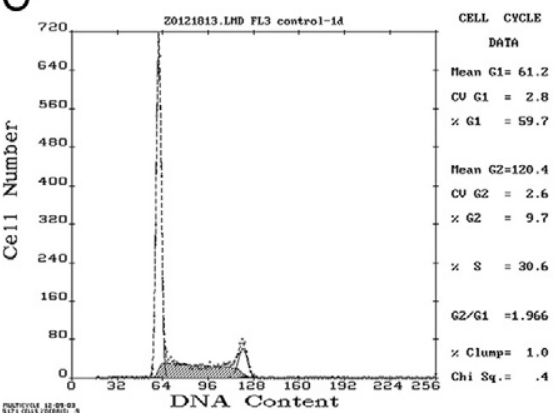

B

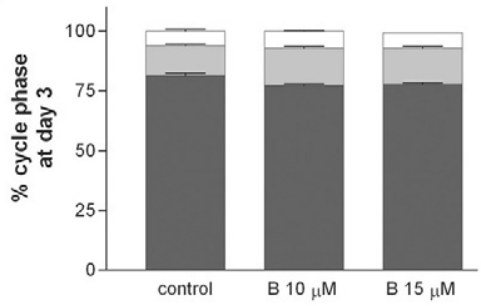

$\square \mathrm{S} \square \mathrm{G} 1$

D

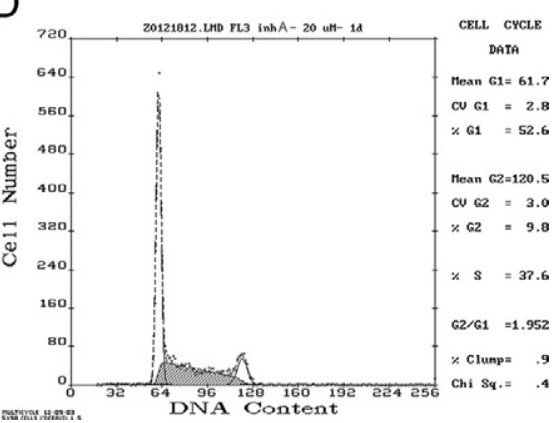

Figure 5. MMP-9 inhibitors disturb the cell cycle. A: After 1 day of incubation in the presence or absence of inhibitor A, cells were labeled with propidium iodide, and the cell cycle was examined by flow cytometry. The percentage of cells in the $\mathrm{S}$ phase increases $(P<0.05$ and $P<0.01$ at the doses of 15 and $20 \mu \mathrm{mol} / \mathrm{L}$, respectively) with the inhibitors in relation to the vehicletreated control. The inhibitor also significantly reduces the percentage of cells in the $\mathrm{G}_{1}$ phase $(P<0.05$ and $P<0.01$ at the doses of 15 and 20 $\mu \mathrm{mol} / \mathrm{L}$, respectively). B: Likewise, the percentages of cells in the $\mathrm{S}$ phase $(P<0.001)$ and $\mathrm{G}_{2}$ phase $(P<0.05)$ increase, whereas that of cells in the $G_{1}$ phase decreased $(P<0.001)$ after a 3-day exposure to inhibitor $B$ at doses of 10 and $15 \mu \mathrm{mol} / \mathrm{L}$. Data are expressed as the mean \pm SEM ( $n=6$ to 4 ) percentage of cells in each cycle phase. Results were analyzed by one-way analysis of variance followed by Dunnett's multiple comparison test to evaluate the effects of treatments against the control. Representative examples of the flow cytometry analysis are shown in $\mathbf{C}$ and $\mathbf{D}$ for a control and for 20 $\mu \mathrm{mol} / \mathrm{L}$ inhibitor A, respectively. examined the cells using the fluorescence microscope after propidium iodide staining, and no signs of increased cell death were observed (not shown).

To validate these findings, we silenced MMP-9 expression with siRNA in SH-SY5Y cells. After silencing of MMP-9, the expression of MMP-9 mRNA was reduced by $36 \%$ versus treatment with nonsilencing RNA (nsRNA), and the expression of the protein was also attenuated (Supplemental Figure 2E, see http://ajp.amjpathol.org). These changes paralleled a concomitant $15 \%$ reduction $(P<0.001)$ in cell growth at day 4 after transfection with siRNA-MMP-9 versus nsRNA (Figure 7E).

We then investigated whether MMP-9 was involved in cell division in the N-Myc-amplified neuroblastoma cell line, SK-N-BE-2C, by silencing MMP-9 expression with siRNA. We achieved a mean reduction in MMP-9 mRNA expression of $44 \%$, as assessed by real-time RT-PCR, and a corresponding 37\% reduction in MMP-9 protein expression versus nsRNA as assessed by Western blotting (Supplemental Figure 2F, see http://ajp.amjpathol.org). This effect also caused a small (15\%), but significant $(P<0.01)$, reduction of cell growth compared with that of cells receiving nonsilencing RNA.

\section{Action of a Growth Factor and Effect of MMP Inhibitors}

Treatment with $10 \mathrm{ng} / \mathrm{ml}$ TGF- $\alpha$ for 6 days (Figure 8, A and $B$ ) increased cell growth and proliferation as revealed by the MTT assay (Figure $8 \mathrm{C}$ ) and by cell counting (Figure 8D), and more mitotic figures were seen after DNA staining with Hoechst 33258 dye $(2.0 \pm 0.08 \%$ mitotic cells) compared with those in controls at the same
A

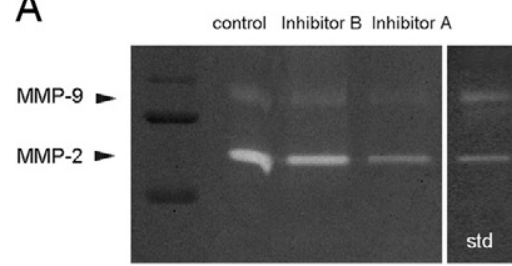

C

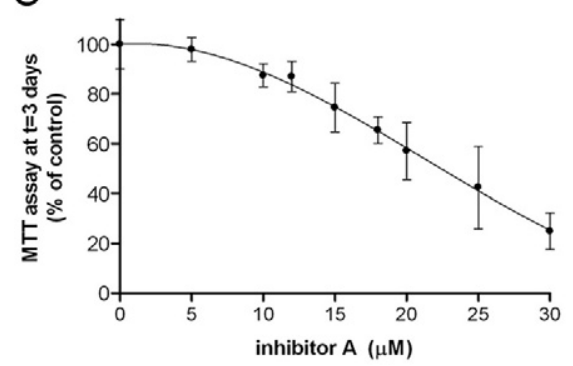

B

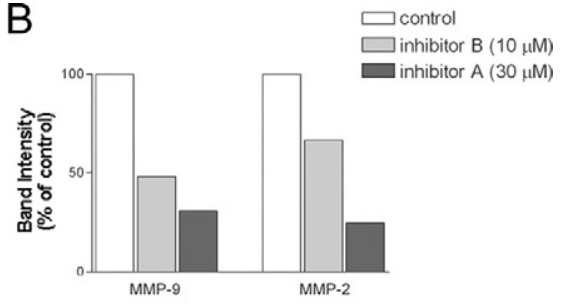

D

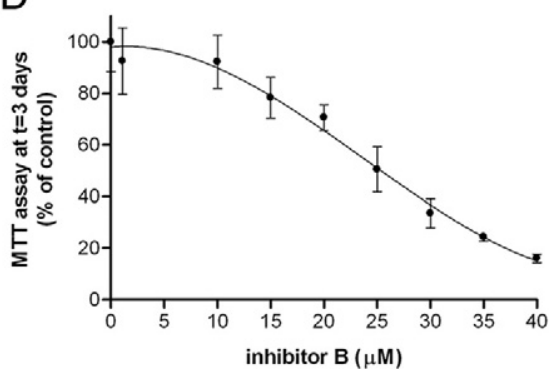

Figure 6. MMP inhibitors reduce cell growth in a concentration-dependent manner. A: Gel zymography shows reduction of gelatinase activity after incubation the cells for 3 days in the presence of the inhibitors. B: Inhibitor A reduces MMP-9 and MMP-2 activity, whereas inhibitor B has a greater effect on MMP-9 than on MMP-2 activity. $\mathbf{C}$ and $\mathbf{D}$ : Concentration-response curves for which the response is evaluated with the MTT assay as an assessment of cell culture growth. Cultures were exposed to the inhibitor for 3 days. C: Effect of inhibitor A with concentrations ranging from 0 to $30 \mu \mathrm{mol} / \mathrm{L}$. D: Effect of inhibitor $\mathrm{B}$ with concentrations ranging from 0 to $35 \mu \mathrm{mol} / \mathrm{L}$. Curves are fit with nonlinear regression to two-phase exponential decay equations using GraphPad Prism software. $R^{2}=0.86$ and 0.87 for inhibitor $\mathrm{A}$ and $\mathrm{B}$, respectively. Each data point is expressed as the percentage of the mean MTT value obtained in the control (3-day vehicle-treated with inhibitor concentration $=0$ ) and is the mean $\pm \mathrm{SD}$ of $n=6$ to 18 values obtained in two to three independent experiments. 
A

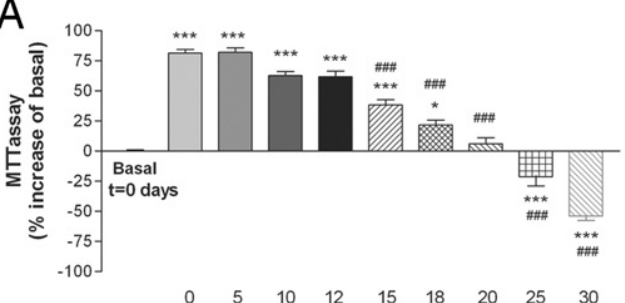

inhibitor $\mathrm{A}(\mu \mathrm{M}) \mathrm{t}=3$ days
B

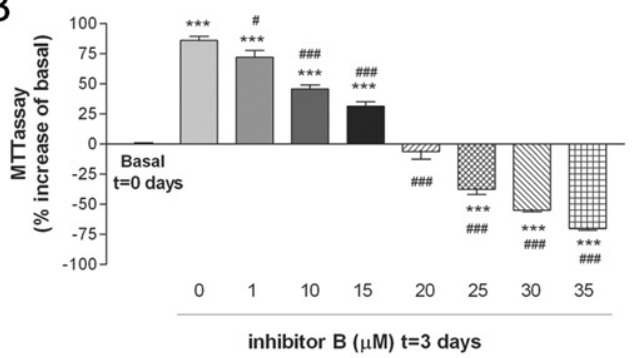

E

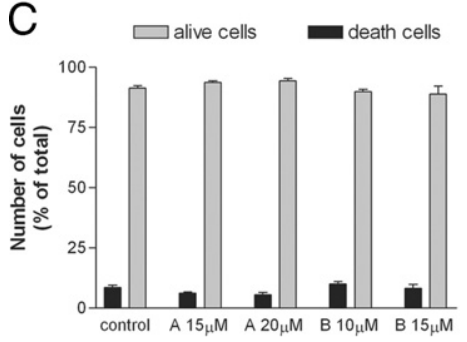

D
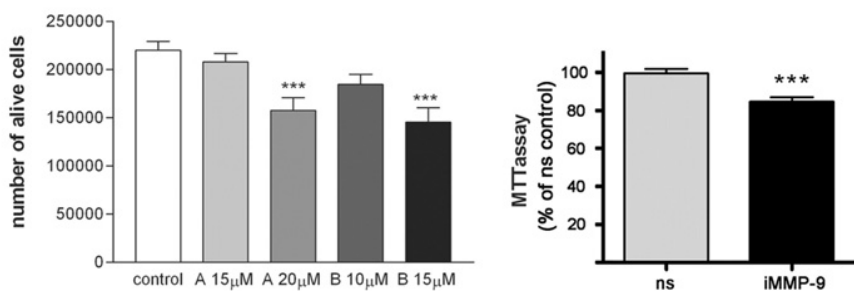

Figure 7. MPP inhibitors reduce cell growth but only promote cell death at high doses after a 3-day exposure. Cells were exposed to the MMP inhibitors from day 0 to day 3 , and then cell growth was assessed with the MTT assay. The MTT value was compared with the basal MTT at time $0 .{ }^{*}$ and ${ }^{*}$, Comparison versus basal MTT at time 0 and control MTT at day 3, respectively. After 3 days in culture, MTT values increased in the controls by approximately $75 \%$ above basal $(P<0.001)$. A: From the concentration of $15 \mu \mathrm{mol} / \mathrm{L}$, inhibitor A reduces the 3-day MTT value in relation to the control $\left(0 \mu\right.$ mol/L inhibitor; $\left.{ }^{*}\right)$. Increasing concentrations of inhibitor A progressively reduce the 3-day increase in relation to basal MTT (*). No increase above basal MTT is seen at $20 \mu \mathrm{mol} / \mathrm{L}$, and a reduction below basal is seen from the concentration of $25 \mu \mathrm{mol} / \mathrm{L}$. B: From the concentration of $1 \mu \mathrm{mol} / \mathrm{L}$, inhibitor B reduces the 3-day MTT value in relation to the control $\left(0 \mu \mathrm{mol} / \mathrm{L}\right.$ inhibitor; $\left.{ }^{*}\right)$. Increasing concentrations of inhibitor B progressively reduce the 3-day increase in relation to basal MTT $(*)$. No increase above basal MTT is seen at $20 \mu \mathrm{mol} / \mathrm{L}$, and a reduction below basal is seen from the concentration of $25 \mu \mathrm{mol} / \mathrm{L}$. Values in $\mathbf{A}$ and $\mathbf{B}$ are expressed as percentage of increase or reduction in relation to basal MTT at time 0 and are the mean \pm SEM of $n=6$ to 18 values per group obtained in two to three independent experiments. C: The mean \pm SEM percentage of dead and living cells in relation to total cell number in the culture is not altered by 3 -day exposure to MMP inhibitors ( $n=8$ values per group obtained in two independent experiments). $\mathbf{D}$ : In agreement with results of the MTT assay, the trypan blue dye exclusion assay shows that the absolute number of live cells per well (in a 12 -well plate) is reduced ( $P<$ 0.001) after exposure to either $20 \mu \mathrm{mol} / \mathrm{L}$ inhibitor A or $15 \mu \mathrm{mol} / \mathrm{L}$ inhibitor B. Results were analyzed with one-way analysis of variance followed by Dunnett's multiple comparison test to evaluate the effects of treatments against the control. E: SH-SY5Y neuroblastoma cells were transfected with either siRNA against MMP-9 (siRNA-MMP9) or with nsRNA. After 4 days, cell number was assessed with the MTT assay, and values are expressed as a percentage of nsRNA as the control. Statistical analysis with Student's $t$-test showed a significant reduction in cell growth after silencing of MMP-9 $(P<0.001)$.

time point $(1.4 \pm 0.10 \%$ mitotic cells). TGF- $\alpha$-induced cell growth was dependent on the activity of the EGFR, as inhibition of the receptor tyrosine kinase activity with 10 $\mu \mathrm{mol} / \mathrm{L} 4,5$-dianilinophthalimide reduced cell growth $(P<$ 0.001 ) and returned growth rate to control values (Figure 9E). Exposure of cultures treated with TGF- $\alpha$ to MMP inhibitors for 2 days significantly reduced MTT values in a dose-dependent manner (Figure 8, F and G), suggesting that MMP activity supports neuroblastoma culture cell growth under a variety of conditions bearing different cell growth rates.

Western blotting showed the prozymogen form of MMP-9 as a $94-\mathrm{kDa}$ band together with a fainter band of lower molecular mass (approximately $88 \mathrm{kDa}$ ) that was associated with proteolytic cleavage of the proform (Figure 8A). TGF- $\alpha$ enhanced cleavage of the proform and expression of the lower molecular mass form (Figure $8 \mathrm{H}$ ). Zymography assays of cellular gelatinase extracts (Figure 8I) revealed that TGF- $\alpha$ enhanced gelatin degradation and appearance of a band of approximately $88 \mathrm{kDa}$, thus corresponding to an active MMP-9 form. These results suggest that MMP-9 is further activated in neuroblastoma cells with a higher growth rate after TGF- $\alpha$-treatment.

\section{MMP-9 Expression in Primary Cultures of Macrophages}

To test whether the above findings in neuroblastoma cells were also seen in other cells, we examined primary cul- tures of macrophages obtained from rat bone marrow. Macrophages were stained with MMP-9 antibodies and again higher cellular MMP-9 expression was detected in dividing cells (Figure 9, A-F). To verify antibody specificity we preabsorbed the antibody with human recombinant MMP-9 and found lower intensity of staining under these conditions (Supplemental Figure 3, see http://ajp. amjpathol.org). In addition, in situ zymography showed increased gelatinase activity in dividing cells (Figure 9G), whereas gelatinase activity was lost in the presence of a broad-spectrum MMP inhibitor (1,10-phenanthroline monohydrate) (Figure 9H). These findings suggest that MMP expression and activity are increased in macrophages undergoing mitosis.

In an attempt to increase the numbers of dividing macrophages, we starved the cells from L-cell for 18 hours and then replaced the L-cell conditioned medium. Cells were harvested at different time points ranging from 0 to 24 hours to study the cell cycle by flow cytometry and the cellular expression of MMP-9 mRNA and protein by real-time RT-PCR and Western blotting, respectively. This procedure allowed increasing the percentage of cells in the $S$ phase from 5 to $10 \%$ up to $22 \%$, at most. We then examined whether increases in the number of cells undergoing cell division were related to increases in MMP-9 expression. We found that the content of MMP-9 protein was positively correlated with the percentage of cells in the $S$ phase (linear regression analysis, $P<0.001$ ) (Figure 10A). A similar positive relationship was found for 
A

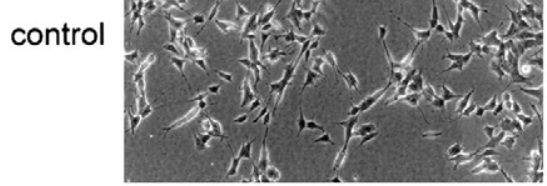

C

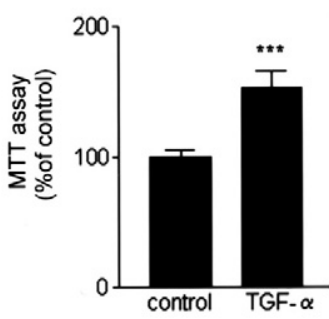

F

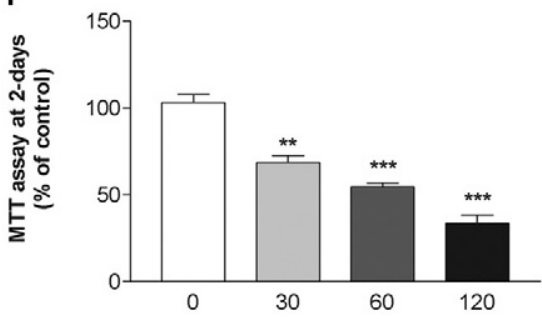

inhibitor-A $(\mu \mathrm{M})$ in the presence of TGF- $\alpha$

$\mathrm{H}$

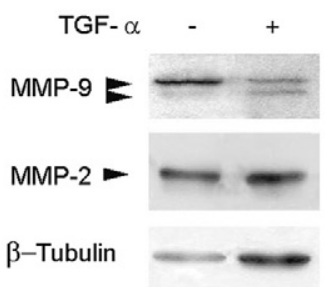

D
B

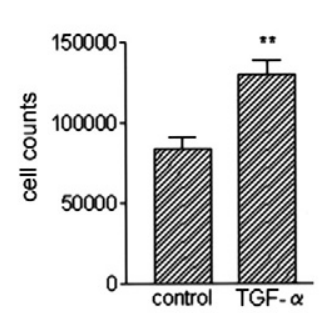

E

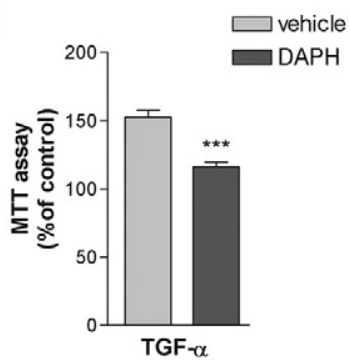

G

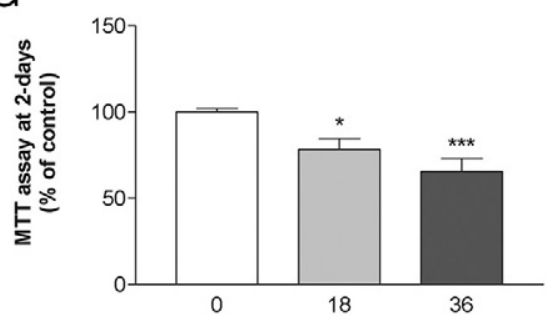

inhibitor-B $(\mu \mathrm{M})$ in the presence of TGF- $\alpha$
Figure 8. TGF- $\alpha$ enhances cell growth in an MMP-dependent manner. A: Microscopic phasecontrast images of SH-SY5Y cells after 6 days in culture under control conditions. B: Microscopic phase-contrast images after exposure to 10 $\mathrm{ng} / \mathrm{ml}$ TGF- $\alpha$, a ligand of EGFR. Scale bar $=50$ $\mu \mathrm{m}$. MTT assay (expressed as a percentage of control) (C) and total cell counts per well (trypan blue exclusion assay) (D) show that TGF- $\alpha$ increases cell growth. E: 4,5-Dianilinophthalimide (DAPH), an inhibitor of the tyrosine kinase activity of the EGFR, inhibits TGF- $\alpha$-induced cell growth, showing that the effect of TGF- $\alpha$ is mediated through EGFR. F and G: MTT assay after exposure to various concentrations of MMP inhibitor A (F) and inhibitor B (G) in the presence of TGF- $\alpha$. TGF- $\alpha$-treated cells are sensitive to the effect of MMP inhibitors as they reduce cell growth. H: Western blot analysis of cell protein extracts shows a 94-kDa band of MMP-9 corresponding to the proform, together with a faint band at lower molecular mass (approximately $88 \mathrm{kDa}$ ). The intensity of this latter band is enhanced by the presence of TGF- $\alpha$ (10 $\mathrm{ng} / \mathrm{ml}$ ), whereas the intensity of the proform band tends to decrease with this treatment. I: Zymographic analysis of cellular extracts (see Materials and Methods) shows that MMP-9 activity is enhanced in the presence of TGF- $\alpha$. std, molecular mass standards. Comparison agains control: ${ }^{*} P<0.05 ;{ }^{* *} P<0.001 ;{ }^{* * * *} P<0.0001$.
MMP-9 mRNA and numbers of dividing cells (linear regression analysis, $P<0.001$ ) (Figure 10B).

To determine whether there was a causal relationship between MMP-9 expression and cell division, we silenced MMP-9 by transfection with small interfering RNA (MMP9-siRNA). Controls included cells transfected with a control nonsilencing RNA sequence (ns-siRNA) and cells subjected to the transfection process but untreated (mock). Treatment with siRNA against MMP-9 reduced the expression of MMP-9 mRNA by approximately $80 \%$ (not shown), and it also reduced MMP-9 protein expression (Figure 10, C and D). After MMP-9 silencing, the growth of macrophages from L0 to $L 4$ was significantly reduced by approximately $70 \%$ compared with that in controls (Figure 10E). We verified that these treatments did not induce cell death by measuring lactate dehydrogenase released to the medium (not shown). Finally, we examined the effect of either the broad-spectrum MMP inhibitor GM6001 or EDTA in gel zymography. Incubation of the zymography gels after electrophoresis with either EDTA or the MMP inhibitor fully prevented the activity of
MMP-9 and MMP-2 (Figure 10F). Taken altogether, these results show that expression of intracellular MMP-9 increases in dividing macrophages and that MMP-9 participates in the process of macrophage cell growth, thus suggesting that intracellular MMP-9 may be involved in cell division.

\section{Treatment with Recombinant MMP-9}

To investigate whether exogenous MMP-9 might be involved in the above effects, we incubated macrophages and SK-N-BE-2C neuroblastoma cells with rMMP-9 (50 or $100 \mathrm{ng} / \mathrm{ml}$ ) after withdrawal of gelatinases from the serum. MMP-9 was successfully removed by incubating the serum with gelatin-Sepharose beads (Supplemental Figure 4A, see http://ajp.amjpathol.org). Cells were exposed to medium containing either normal serum or serum without gelatinases, the latter in the presence or absence of added rMMP-9. On the next day, cell growth under the different conditions was examined and compared. Exog- 

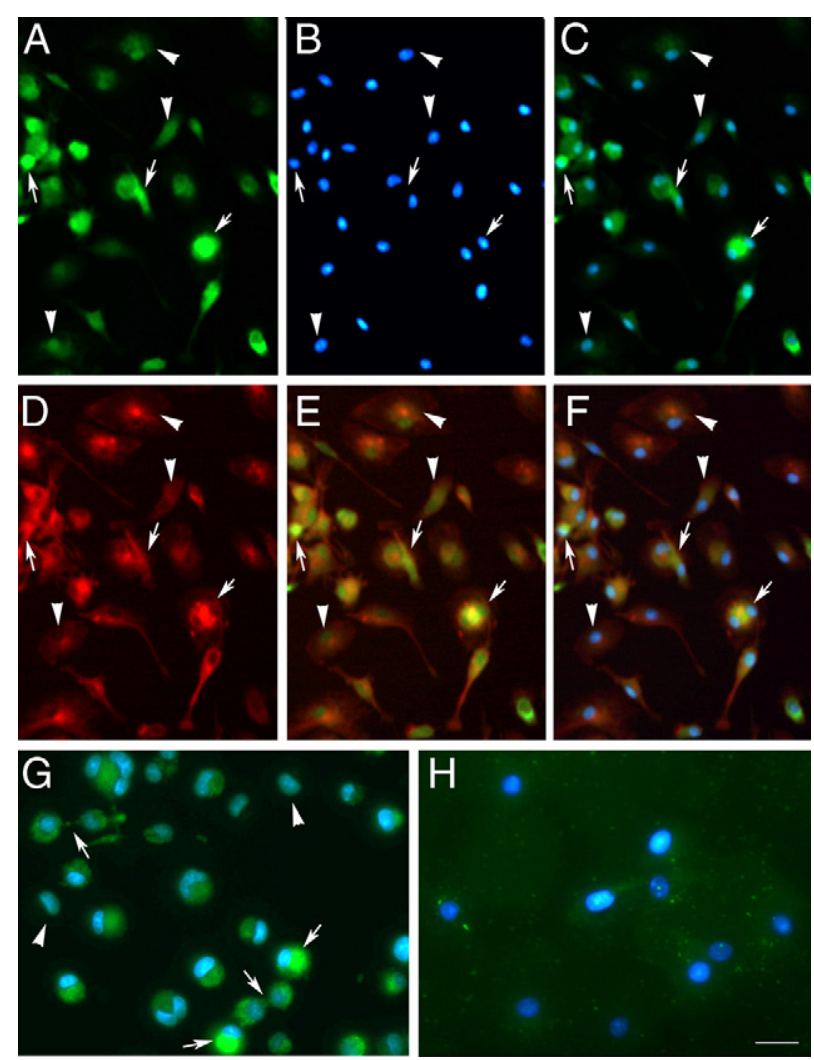

Figure 9. Immunocytochemistry and in situ zymography show that dividing macrophages have a higher content/activity of MMP-9 than resting cells. Results of immunocytochemistry are shown in $\mathbf{A}-\mathbf{F}$ and in situ zymography is shown in $\mathbf{G}$ and $\mathbf{H}$. Images were obtained with the fluorescence microscope. A: Immunocytochemistry for MMP-9 (antibody ab76003 from Abcam) (green) in primary cultures of macrophages shows higher expression in certain cells (arrows) compared with others (arrowheads). B: DNA Hoechst staining (blue) corresponding to the image in A. C: Merged MMP-9 (green) and Hoechst (blue) staining shows that cells with higher MMP-9 expression are dividing cells (arrows). D: $\beta$-Tubulin (red) staining of the same images shown in A-C. E: Merged $\beta$-tubulin (red) and MMP-9 (green) staining. F: Merged $\beta$-tubulin, MMP-9, and Hoechst staining of the previous images. G: In situ zymography showing higher gelatinase activity (green) in dividing cells (arrows) than in resting cells (arrowheads). H: A broadspectrum MMP inhibitor prevents gelatinase activity in the macrophages. Hoechst staining is shown in blue. Arrows point to dividing cells with high MMP-9 immunoreactivity, whereas arrowheads point to cells with comparatively lower intensity of MMP-9 immunostaining. Scale bars: $50 \mu \mathrm{m}(\mathbf{A}-\mathbf{F})$; $20 \mu \mathrm{m}(\mathbf{G}$ and $\mathbf{H})$.

enous rMMP-9 did not increase cell growth in macrophages or in neuroblastoma cells (Supplemental Figure 4, B and C, see http://ajp.amjpathol.org).

\section{Discussion}

The results of this study support the fact that MMPs play some function during cell division in neuroblastoma cells and in primary cultures of macrophages. Stronger gelatinase activity and MMP-9 immunoreactivity were detected in cells undergoing mitosis than in resting cells. This positive reaction was distributed around the chromosomes in a dynamic and well orchestrated fashion at the different mitotic stages. In addition, MMP inhibitors disturbed the cell cycle, preventing cells from entering the $S / G_{2}$ phase of cell division, and subsequently these inhibitors reduced cell culture growth and so did silenc- ing of MMP-9 expression. In addition, stimulation of cell proliferation with a growth factor, TGF- $\alpha$, was associated with intracellular MMP activation. The present results suggest that this MMP might participate in several steps of cell division in a highly controlled manner, because of the precise and dynamic intracellular distribution of MMP-9 immunoreactivity during mitosis. Therefore, we hypothesize that MMPs might be involved in certain mitotic steps, such as rearrangement of the cellular matrix, breaking down the nuclear envelope, and/or chromatid segmentation.

Previous studies showed that MMPs may play a role in intracellular functions. Indeed, MMP-1 is strongly associated with mitochondria and nuclei, and it accumulates within the cells during the mitotic phase of the cell cycle. ${ }^{27}$ Membrane type $1 \mathrm{MMP}$ has been shown to be trafficked along the tubulin cytoskeleton, to have an intracellular cleavage function, and to cause chromatin instability. ${ }^{20}$ Intracellular MMP-2 has been associated with injury after acute myocardial ischemia/reperfusion, ${ }^{28}$ and tissue inhibitor of MMP-2 exerts an antimitotic action. ${ }^{29}$ In addition, the presence of several MMPs in the cell nucleus under pathological conditions has been reported. For instance, atypical localization of membrane type 1-matrix metalloproteinase in the nucleus is associated with aggressive features of hepatocellular carcinoma. ${ }^{30}$ MMP-3 is found in the nucleus and nuclear MMP-3 induced apoptosis via its catalytic activity. ${ }^{31}$ In addition, MMP-2 is present in the nucleus of cardiac myocytes and is capable of cleaving poly(ADP-ribose) polymerase in vitro. $^{21}$

In the present study, we report increased MMP-9 immunoreactivity in dividing cells, with the highest activity at the early phases of mitosis. As cell division progressed and the mitotic spindle was formed, it became apparent that MMP-9 immunoreactivity was located surrounding the microtubules. As in the prometaphase, the nuclear membrane disintegrates ${ }^{32}$ and the possibility that MMP-9 activity might contribute to nuclear membrane breakdown and/or nuclear matrix reorganization deserves further exploration. The structure located between the inner nuclear membrane and the peripheral chromatin is called nuclear lamina, which, besides maintaining nuclear architecture, is an important cell cycle regulator. ${ }^{33}$ It is composed of lamins, the nucleolus, and nuclear matrix proteins arranged in a fibrillogranular network. ${ }^{34}$ The nuclear lamina interacts with the chromatin, ${ }^{35,36}$ and it is disassembled during mitosis. ${ }^{37}$ Of interest, the nuclear matrix structure is substantially altered by malignancy. ${ }^{38}$ During the progression from metaphase to anaphase, when spindle length increases, MMP-9 immunoreactivity appeared between the two chromatids as they progressively separated from each other toward the opposite poles of the mitotic spindle. This location indicates that MMP activity might participate in cellular matrix rearrangement to facilitate separation of the sister chromatids, which is essential to allow precise chromosome segregation. ${ }^{39}$ However, the mechanism that controls this process is not yet fully understood, and certain proteases that participate in sister chromatid separation remain unidentified. In addition, identification of targets of 
A

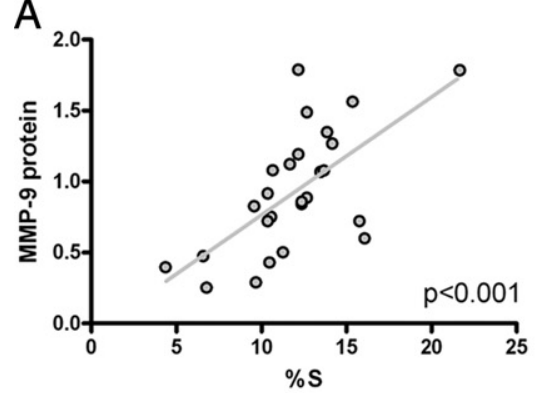

D

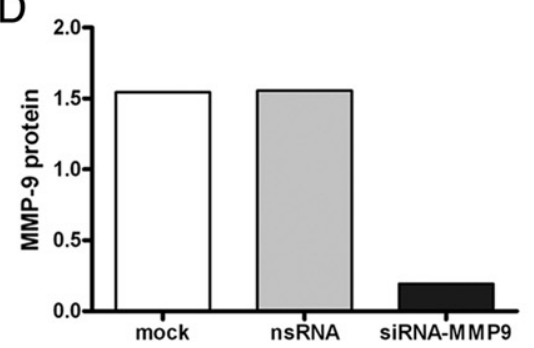

B

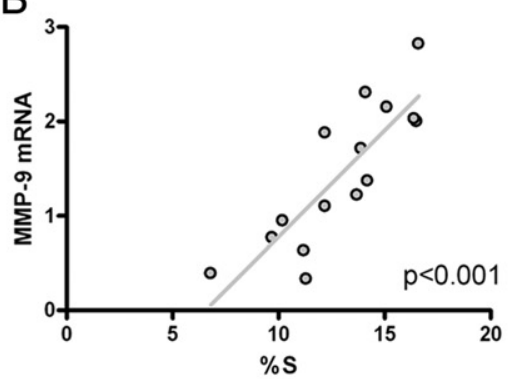

E

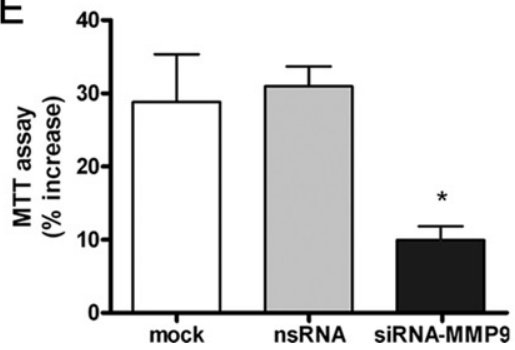

C

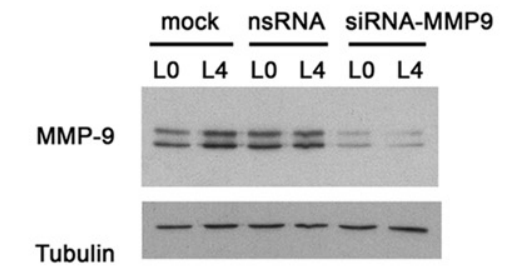

$\mathrm{F}$

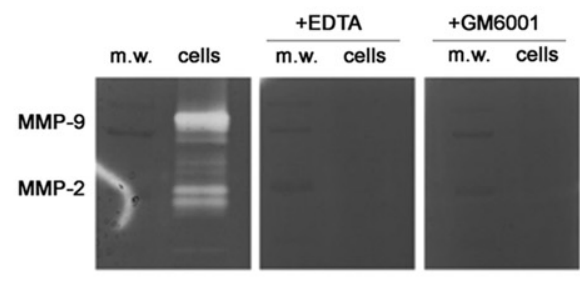

Figure 10. MMP-9 expression in relation to cell division in macrophages. A and B: Macrophages were subjected to L-cell starvation for 18 hours and then incubated again with the conditioned medium from different time periods ranging from 6 to 24 hours. Then cells were harvested, and a part of the cells was used to study the cell cycle by flow cytometry and the other was used to study the expression on MMP-9 protein by Western blotting (antibody ab76003 from Abcam) (A) or RNA by real-time RT-PCR (B). A: The content of MMP-9 was significantly correlated with the percentage of cells in the S phase (linear regression analysis, $P<0.001$ ). The MMP-9 band intensity in each lane of the Western blot was measured, and it was normalized by the corresponding band intensity of $\beta$-tubulin. Points in the graph correspond to single values and were obtained in four independent experiments. B: The MMP-9 RNA content was studied by real-time RT-PCR. Expression of MMP-9 RNA was positively correlated with the percentage of cells entering the cell cycle (linear regression analysis, $P<0.001$ ). Points in the graph correspond to single values and were obtained in two independent experiments. C-E: MMP-9 expression was silenced with siRNA. Cells were exposed to either mock treatment, nsRNA, or siRNA against MMP-9 (siRNA-MMP9) for 1 day. After that, cells were subjected to L-cell starvation for 18 hours (L0) and incubated again with L-cell conditioned medium for 22 hours (L4). C: An image of a representative Western blot is shown. The experiment was repeated twice. D: Corresponding quantification of MMP-9 protein at stage L4 is shown to demonstrate that siRNA-MMP9 treatment effectively reduced MMP-9 expression. E: The percent increase in cell number from L0 to L4 was assessed with the MTT assay after the different treatments ( $n=3$ per treatment). Data of a representative experiment of two independent experiments are shown. One-way analysis of variance followed by the Bonferroni post hoc test showed a significant reduction of cell growth after silencing of MMP-9 expression. ${ }^{*} P<0.05$. F: Gelatin zymography shows MMP-9 and MMP-2 activity in cell extracts of macrophages and the complete inhibitory effect of either the broad spectrum MMP inhibitor GM6001 $(10 \mu \mathrm{mol} / \mathrm{L})$ or EDTA $(10 \mathrm{mmol} / \mathrm{L})$ that was added to the incubation medium of the gels after electrophoresis. m.w., molecular weight.

intracellular MMP-9 during cell division would help in understanding the role of this protease in this process and whether alterations of its action might be involved in cell cycle misregulation in tumor cells.

Our study provides evidence for increased expression of MMP-9 in dividing cells. However, this effect was not restricted to tumor cells, such as human neuroblastoma cells, because it was also observed in primary cultures of rat bone marrow-derived macrophages. Previous studies showed that angiogenesis and tumor progression were attenuated in MMP-9-deficient mice. ${ }^{40}$ However, transplantation of bone marrow-derived CD45-positive leukocytes expressing MMP-9 was sufficient to restore the tumor phenotype in MMP-9 knockout mice, showing the importance of the MMP-9 secreted by macrophages in tumor progression. ${ }^{40}$ Here, treatment with TGF- $\alpha$, a mitogenic growth factor acting at the EGFR, ${ }^{17,18,41}$ increased cell growth and proliferation though an EGFR-dependent signaling pathway and caused MMP-9 activation, in agreement with previous results showing that EGFR activates MMP-9. ${ }^{12-15}$ In contrast, MMP-9 inhibitors reduce tumor cell growth. ${ }^{5,6,42}$ TGF- $\alpha$-induced cell growth was also sensitive to the action of MMP-9 inhibitors, thus suggesting that MMP-9 activation was involved in this process. In addition, MMP inhibitors and genetic MMP-9 deficiency reduce angiogenesis, and tumor number and growth during carcinogenesis of pancreatic islets. ${ }^{43}$ In our study, we did not find evidence that the reported effects were attributable to exogenous MMP-9. Further studies are needed to better understand how intracellular MMP-9 might be involved in cell division and whether it might have some influence on tumor growth.

The present findings are based on the use of several monoclonal antibodies against MMP-9, examination of gelatinase activity by zymography (in situ and gel), and the use of MMP inhibitors. These tools have some limitations because the drug inhibitors not only inhibit MMP-9 but gelatinolytic activity might also be due to various proteases, and we cannot completely exclude the possibility that the monoclonal antibodies might recognize MMP-9-like proteins. For this reason we silenced the expression of MMP-9. Preventing MMP-9 expression reduced the rate of cell growth, thus suggesting that MMP-9 was involved in this process.

Taken altogether, the present results support the participation of intracellular MMP-9 in certain steps of cell division in the human neuroblastoma cells and in primary cultures of rat macrophages.

\section{Acknowledgments}

We are grateful to Jaume Comas, Roser Garcia, and Anna Bosch (Serveis Científico-Tècnics of the University 
of Barcelona) for excellent technical support. We are indebted to Dr. Joan Serratosa (Institut d'Investigacions Biomèdiques de Barcelona-Consejo Superior de Investigaciones Científicas, Institut d'Investigacions Biomèdiques August $\mathrm{Pi}$ i Sunyer) for kindly providing cultures of mouse fibroblasts and to Dr. Jaume Mora (Hospital de Sant Joan de Deu, Barcelona) for providing the SK-N-BE-2C neuroblastoma cell line. We thank Mr. Luca Maggione for technical assistance.

\section{References}

1. Springman EB, Angleton EL, Birkedal-Hansen $\mathrm{H}$, Van Wart HE: Multiple modes of activation of latent human fibroblast collagenase: evidence for the role of a Cys73 active-site zinc complex in latency and a "cysteine switch" mechanism for activation. Proc Natl Acad Sci USA 1990, 87:364-368

2. Woessner JF Jr: Matrix metalloproteinases and their inhibitors in connective tissue remodeling. FASEB J 1991, 5:2145-2154

3. Yong VW, Krekoski CA, Forsyth PA, Bell R, Edwards DR: Matrix metalloproteinases and diseases of the CNS. Trends Neurosci 1998, 21:75-80

4. Stetler-Stevenson WG: Type IV collagenases in tumor invasion and metastasis. Cancer Metastasis Rev 1990, 9:289-303

5. Tonn JC, Kerkau S, Hanke A, Bouterfa H, Mueller JG, Wagner S, Vince $\mathrm{GH}$, Roosen K: Effect of synthetic matrix-metalloproteinase inhibitors of invasive capacity and proliferation of human malignant gliomas in vitro. Int J Cancer 1999, 80:764-772

6. Rabbani SA, Harakidas P, Guo Y, Steinman D, Davidsen SK, Morgan DW: Synthetic inhibitor of matrix metalloproteases decreases tumor growth and metastases in a synergic model of rat prostate cancer in vivo. Int J Cancer 2000, 87:276-282

7. Yamashita T, Fujii M, Tomita T, Ishiguro R, Tashiro M, Tokumaru $Y$, Imanishi Y, Kanke M, Ogawa K, Kameyama K, Otani Y: The inhibitory effect of matrix metalloproteinase inhibitor ONO-4817 on lymph node metastasis in tongue carcinoma. Anticancer Res 2003, 23:2297-2302

8. Moon SK, Cha BY, Kim CH: In vitro cellular aging is associated with enhanced proliferative capacity. G1 cell cycle modulation, and matrix metalloproteinase- 9 regulation in mouse aortic smooth muscle cells. Arch Biochem Biophys 2003, 418:39-48

9. Aoudjit F, Masure S, Opdenakker G, Potworowski E, St-Pierre Y: Gelatinase B (MMP-9), but not its inhibitor (TIMP-1), dictates the growth rate of experimental thymic lymphoma. Int J Cancer 1999, 82:743-747

10. Rooprai HK, Rucklidge GJ, Panou C, Pilkington GJ: The effects of exogenous growth factors on matrix metalloproteinase secretion by human brain tumour cells. Br J Cancer 2000, 82:52-55

11. Miettinen PJ, Chin JR, Shum L, Slavkin HC, Shuler CF, Derynck R, Werb Z: Epidermal growth factor receptor function is necessary for normal craniofacial development and palate closure. Nat Genet 1999, 22:69-73

12. Kondapaka SB, Fridman R, Reddy KB: Epidermal growth factor and amphiregulin up-regulate matrix metalloproteinase-9 (MMP-9) in human breast cancer cells. Int J Cancer 1997, 70:722-726

13. Visscher DW, Sarkar FH, Kasunic TC, Reddy KB: Clinicopathologic analysis of amphiregulin and heuregulin immunostaining in breast neoplasia. Breast Cancer Res Treat 1997, 45:75-80

14. O-charoenrat P, Modjtahedi H, Rhys-Evans P, Court WJ, Box GM, Eccles SA: Epidermal growth factor-like ligands differentially up-regulate matrix metalloproteinase 9 in head and neck squamous carcinoma cells. Cancer Res 2000, 60:1121-1128

15. Reddy KB, Krueger JS, Kondapaka SB, Diglio CA: Mitogen-activated protein kinase (MAPK) regulates the expression of progelatinase $B$ (MMP-9) in breast epithelial cells. Int J Cancer 1999, 82:268-273

16. O-charoenrat P, Rhys-Evans P, Court WJ, Box GM, Eccles SA: Differential modulation of proliferation, matrix metalloproteinase expression and invasion of human head and neck squamous carcinoma cells by c-erb B ligands. Clin Exp Metastasis 1999, 17:631-639

17. Massague J: Epidermal growth factor-like transforming growth factor. II. Interaction with epidermal growth factor receptors in human placenta membranes and A431 cells. J Biol Chem 1983 258:13614-13620

18. Derynck R: Transforming growth factor- $\alpha$. Cell 1988, 54:593-595

19. Ueda M, Ueki M, Terai Y: Morimoto A. Fujii H, Yoshizawa K, Yanagihara $\mathrm{T}$ : stimulatory effects of EGF and TGF- $\alpha$ on invasive activity and 5'-deoxy-5-fluorouridine sensitivity in uterine cervical-carcinoma SKG-IIlb cells. Int J Cancer 1997, 72:1027-1033

20. Golubkov VS, Boyd S, Savinov AY, Chekanov AV, Osterman AL, Remacle A, Rozanov DV, Doxsey SJ, Strongin AY: Membrane type-1 matrix metalloproteinase (MT1-MMP) exhibits an important intracellular cleavage function and causes chromosome instability. J Biol Chem 2005, 280:25079-25086

21. Kwan JA, Schulze CJ, Wang W, Leon $H$, Sariahmetoglu M, Sung M, Sawicka J, Sims DE, Sawicki G, Schulz R: Matrix metalloproteinase-2 (MMP-2) is present in the nucleus of cardiac myocytes and is capable of cleaving poly (ADP-ribose) polymerase (PARP) in vitro. FASEB $J$ 2004, 18:690-692

22. Valledor AF, Arpa L, Sánchez-Tilló E, Comalada M, Casals C, Xaus J, Caelles C, Lloberas J, Celada A: IFN- $\gamma$-mediated inhibition of MAPK phosphatase expression results in prolonged MAPK activity in response to M-CSF and inhibition of proliferation. Blood 2008, 112:3274-3282

23. Zhang JW, Gottschall PE: Zymographic measurement of gelatinase activity in brain tissue after detergent extraction and affinity-support purification. J Neurosci Methods 1997, 76:15-20

24. Planas AM, Solé S, Justicia C, Rodríguez-Farré E: Estimation of gelatinase content in rat brain: effect of focal ischemia. Biochem Biophys Res Commun 2000, 278:803-807

25. Planas AM, Solé S, Justicia C: Expression and activation of matrix metalloproteinase-2 and -9 in rat brain after transient focal cerebral ischemia. Neurobiol Dis 2001, 8:834-846

26. Planas AM, Justicia C, Solé S, Friguls B, Cervera A, Adell A, Chamorro A: Certain forms of matrix metalloproteinase- 9 accumulate in the extracellular space after microdialysis probe implantation and middle cerebral artery occlusion/reperfusion. J Cereb Blood Flow Metab 2002, 22:918-925

27. Limb GA, Matter K, Murphy G, Cambrey AD, Bishop PN, Morris GE, Khaw PT: Matrix metalloproteinase-1 associates with intracellular organelles and confers resistance to lamin $A / C$ degradation during apoptosis. Am J Pathol 2005, 166:1555-1563

28. Wang W, Schulze, CJ, Suarez-Pinzon WL, Dyck JRB, Sawicki G, Schulz R: Intracellular action of matrix metalloproteinase-2 accounts for acute myocardial ischemia and reperfusion injury. Circulation 2002, 106:1543-1549

29. Pérez-Martínez L, Jaworski DM: Tissue inhibitor of metalloproteinase-2 promotes neuronal differentiation by acting as an anti-mitotic signal. J Neurosci 2005, 25:4917-4929

30. Ip YC, Cheung ST, Fan ST: Atypical localization of membrane type 1-matrix metalloproteinase in the nucleus is associated with aggressive features of hepatocellular carcinoma. Mol Carcinog 2007 , 46:225-230

31. Si-Tayeb K, Monvoisin A, Mazzocco C, Lepreux S, Decossas M, Cubel G, Taras D, Blanc JF, Robinson DR, Rosenbaum J: Matrix metalloproteinase 3 is present in the cell nucleus and is involved in apoptosis. Am J Pathol 2006, 169:1390-401

32. Gönczy P: Nuclear envelope: torn apart at mitosis. Curr Biol 2002, 12:R242-244

33. Loidl $P$, Eberharter A: Nuclear matrix and the cell cycle. Int Rev Cytol 1995, 162B:377-403

34. Bosman FT: The nuclear matrix in pathology. Virchows Arch 1999, 435:391-399

35. Goldberg M, Harel A, Gruenbaum Y: The nuclear lamina: molecular organization and interaction with chromatin. Crit Rev Eukaryot Gene Expr 1999, 9:285-293

36. Gotzmann J, Foisner R: Lamins and lamin-binding proteins in functional chromatin organization. Crit Rev Eukaryot Gene Expr 1999, 9:257-265

37. Ottaviano $Y$, Gerace L: Phosphorylation of the nuclear lamins during interphase and mitosis. J Biol Chem 1985, 260:624-632

38. Nickerson JA: Nuclear dreams: the malignant alteration of nuclear architecture. J Cell Biochem 1998, 70:172-180

39. Biggins S, Murray AW: Sister chromatid cohesion in mitosis. Curr Opin Cell Biol 1998, 10:769-775 
MMP-9 in Cell Division 2885 AJP December 2010, Vol. 177, No. 6

40. Jodele S, Chantrain CF, Blavier L, Lutzko C, Crooks GM, Shimada H, Coussens LM, Declerck YA: The contribution of bone marrow-derived cells to the tumor vasculature in neuroblastoma is matrix metalloproteinase-9 dependent. Cancer Res 2005, 65:3200-3208

41. Reynolds FH, Todaro GJ, Fryling C, Stephenson JR: Human transforming growth factors induce tyrosine phosphorylation of EGF receptors. Nature 1983, 292:259-262

42. Price A, Shi Q, Morris D, Wilcox ME, Brasher PM, Rewcastle NB,
Shalinsky D, Zou H, Appelt K, Johnston RN, Yong VW, Edwards D, Forsyth P: Marked inhibition of tumor growth in a malignant glioma tumor model by a novel synthetic matrix metalloproteinase inhibitor AG3340. Clin Cancer Res 1999, 5:845-854

43. Bergers G, Brekken R, McMahon G, Vu TH, Itoh T, Tamaki K, Tanzawa K, Thorpe P, Itohara S, Werb Z, Hanahan D: Matrix metalloproteinase-9 triggers the angiogenic switch during carcinogenesis. Nat Cell Biol 2000, 2:737-744 